REVIEW ARTICLE

\title{
Everyday Practice of 2D/3D Vaginal Ultrasound in Reproductive Gynecology
}

\author{
Zorancho Petanovski ${ }^{1}$, Emilija Petanovska Kostova ${ }^{2}$
}

\begin{abstract}
The key point of this review is to evaluate the diagnostic capability of the initial 2D/3D vaginal ultrasound (US) for the most common conditions that have negative impact on the reproductive potential in women. From our experience with 2D/3D transvaginal US as the initial examination in more than 10,000 patients in the last couple of years, we choose specific cases of different pathologies such as fibroids, endometrial polyps, endometrial synechiae, uterine congenital anomalies, polycystic ovaries (PCOs), ovarian follicular monitoring, and endometrial receptivity assessment. Vaginal US is the method of choice for initial examination in evaluation of the reproductive potential in female patients. The 2D vaginal US examination gives only preliminary data, while the 3D vaginal US increases the efficiency and predictive value of the examination. Some pathologies detected on 2D vaginal US such as uterine anomalies, in general, indicate the presence of the anomaly, while 3D vaginal US fully detects the type of uterine anomalies. Doppler techniques bring detection of neovascularization in specific pathologies and give a view of the vascularization in general, which is essential in this field. Combination of 2D and 3D US is a powerful tool in the hands of a gynecologist in everyday practice. Improvement in 3D, 3D Doppler, and power Doppler vaginal US supplemented with new software tools rises the predictive value of US in the diagnosis of female reproductive system pathology and makes it equal with other diagnostic tools such as magnetic resonance imaging. On the contrary, 2D and 3D US examination are less traumatic for the patients and are less expensive.
\end{abstract}

Keywords: 2D/3D ultrasonography, 3D Doppler, Reproductive gynecology.

Donald School Journal of Ultrasound in Obstetrics and Gynecology (2020): 10.5005/jp-journals-10009-1640

\section{INTRODUCTION}

Combination of 2D and 3D ultrasound (US) is a powerful tool in the hands of a gynecologist in everyday practice. We choose specific images of different pathologies such as fibroids, endometrial polyps, endometrial synechiae, uterine congenital anomalies, polycystic ovaries (PCOs), ovarian follicular monitoring, and endometrial receptivity assessment to show how the 2D/3D vaginal ultrasonography evaluates the reproductive potential in female in everyday practice.

\section{LEIOMYOMAS}

A leiomyoma, also known as fibroids (myoma), is a benign smooth muscle tumor that very rarely has malignant potential (leiomyosarcoma). They are built from muscle and fibrous connective tissues and have pseudocapsules rich in blood vessels. These tumors have some US characteristics that include solid masses with same echogenic appearance as the myometrium around them (or hypoechogenic appearance) and generally well isolated from the surrounding tissue, thanks to their pseudocapsule; the intratumoral picture reminds of shadows distributed like spirals in concentric lamellar appearance; according to the presence of calcification in the tumor, there are anechogenic and hypoechogenic shadows behind the tumor which is known as "venetian blind shadowing" sign. The color Doppler shows medium vascularization in the center of the tumor and high vascularization in the periphery ${ }^{1}$ (pseudocapsule) (Figs 1 and 2).

According to localization, they are classified as subserous, intramural, and submucous myomas. Interesting fact is the connection between submucous myomas, infertility, and early miscarriages. Submucous myoma is thought to inhibit endometrial receptivity for implantation. Regarding other types of myomas and the impact on fertility of women as well as pregnancy,
${ }^{1}$ Center for Assisted Reproduction and In Vitro Fertilization, "First Private General Hospital-ReMedika", Skopje, North Macedonia; Medical Faculty, University "GoceDelchev", Shtip, North Macedonia

${ }^{2}$ Center for Assisted Reproduction and In Vitro Fertilization, "First Private General Hospital-ReMedika", Skopje, North Macedonia

Corresponding Author: Zorancho Petanovski, Center for Assisted Reproduction and In Vitro Fertilization, "First Private General HospitalReMedika", Skopje, North Macedonia; Medical Faculty, University "GoceDelchev", Shtip, North Macedonia, Phone: +389 72443 114, e-mail: zpetanovski@yahoo.com

How to cite this article: Petanovski Z, Petanovska Kostova E. Everyday Practice of 2D/3D Vaginal Ultrasound in Reproductive Gynecology. Donald School J Ultrasound Obstet Gynecol 2020;14(2):97-116.

Source of support: First Private General Hospital-ReMedika, Skopje, North Macedonia

Conflict of interest: None

the number, size, and pressure or collision with uterine cavity of myometrium are decisive for possible operative treatment especially in intramural myomas. Studies indicate that intramural myomas greater than $4 \mathrm{~cm}$ have an impact on a woman's fertility potential, while the subserous myoma has no particular effect on the fertility potential. ${ }^{2}$

One classification system is the International Federation for Gynecology and Obstetrics (FIGO), where myomas are classified according tumor localization and distance from cavum uteri and serous part of the uterus. ${ }^{3}$ The European Society for Gynaecological Endoscopy (ESGE) classification system divides submucous myoma into three groups: type 0 entirely within the endometrial cavity, no myometrial extension (pedunculated; Fig. 3); type I, $<50 \%$ myometrial extension (sessile), $90^{\circ}$ angle of the myoma's surface to the uterine wall; and type II >50\% myometrial extension (sessile), 

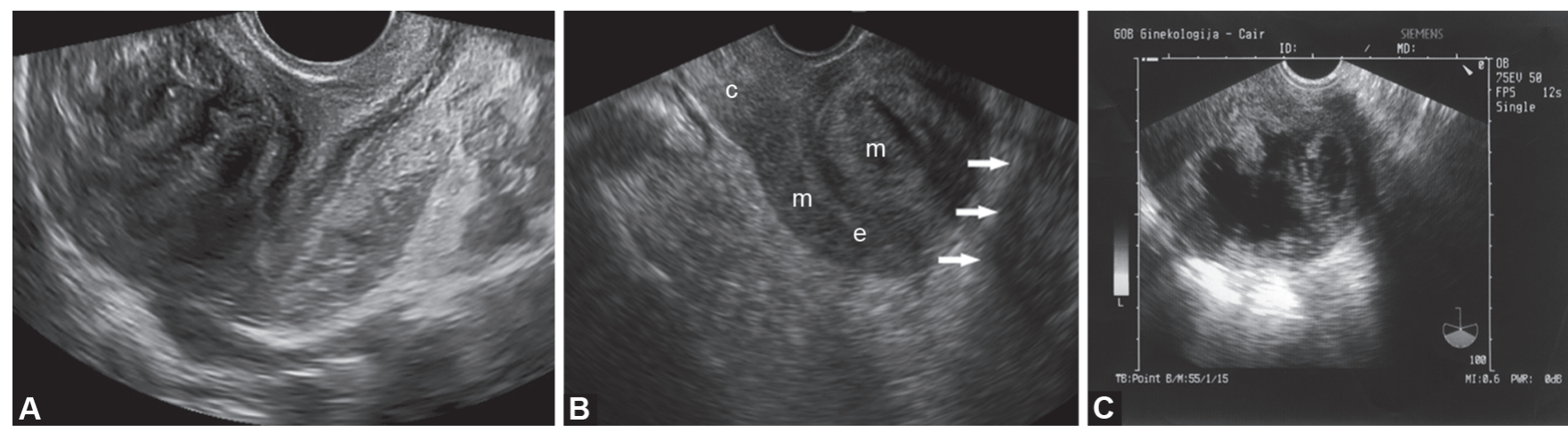

Figs $1 \mathrm{~A}$ to C: The 2D ultarsonograpic characteristics of myomas: (A) Shadows distributed like spirals in concentric lamellar appearance; (B) Sing of "venetian blind shadowing"; (C) Central hypoechogenic area as a result of central tumor degeneration
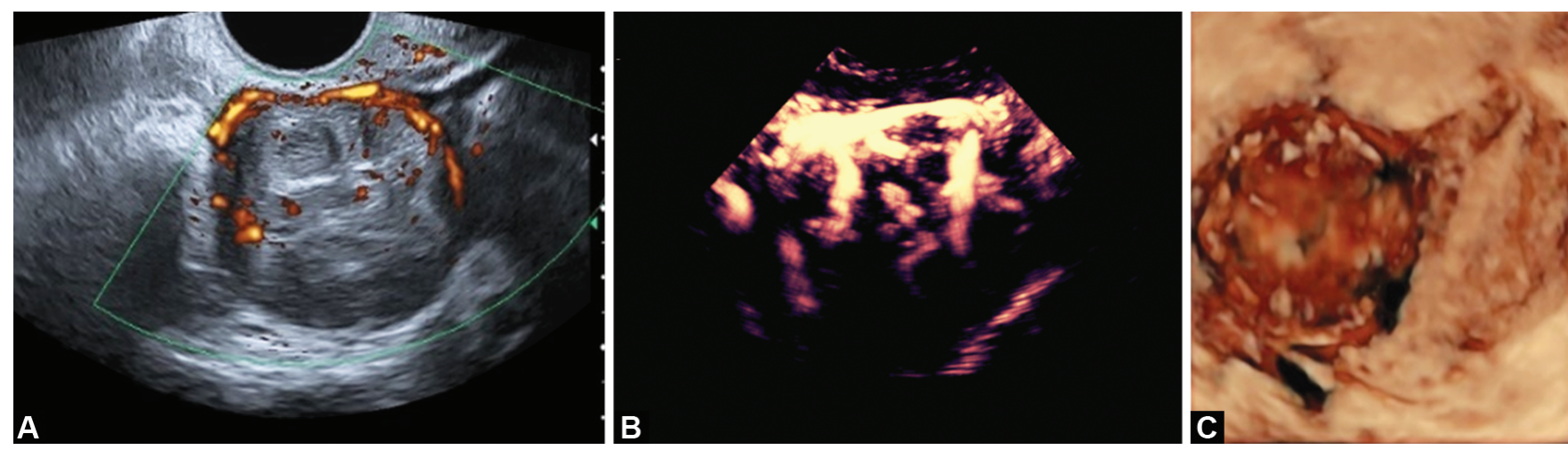

Figs 2A to C: The 2D color Doppler: Rich vascularized presudocapsula ( $A$ and B): peripheral calcification of tumor on 3D vaginal ultrasound (C)
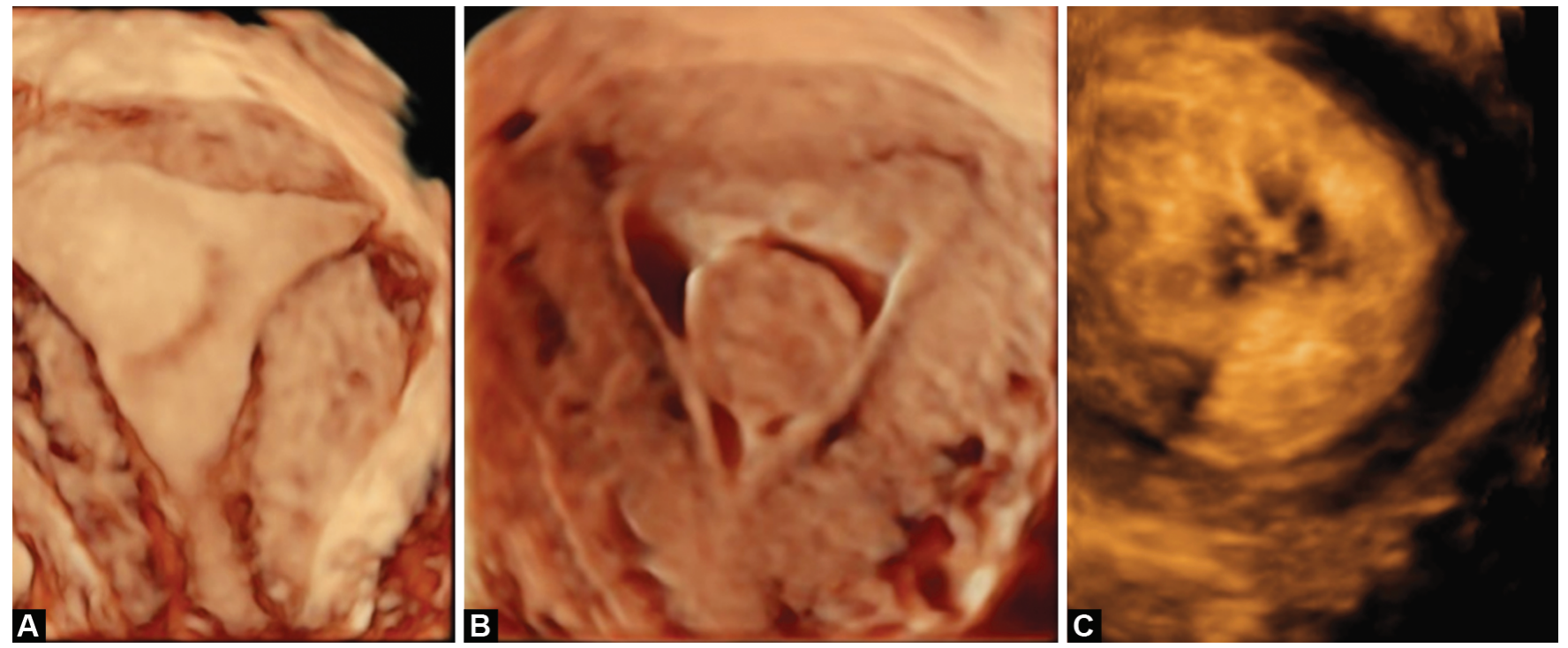

Figs 3A to C: The 3D ultrasound: (A and B) Submucosal, myometrial extension within endometrial cavity, no myometrial extension; (C) High submucosal myoma detected by SIS. FIGO and European Society for Gynaecological Endoscopy type 0

R90 ${ }^{\circ}$ angle of the myoma's surface to the uterine wall ${ }^{4}$ (Figs 3 to 6 ). Both of the systems are simple and provide good information in clinical and research medicine.

Ultrasound plays a very important part in the diagnosis of this uterine pathology in the following manner: by distinguishing myomas from other pathologies such as adenomyosis, endometrial polyps, or rare conditions like uterine hemangioma (Fig. 7) and by recognizing malignant potential in this tumor as $\operatorname{sarcoma}^{5}$ (Fig. 8).

\section{Endometrial Polyp}

Endometrial polyp, in general, is a benign condition presented on $2 \mathrm{D}$ vaginal US as a partial formation with same thickening as endometrium, or in some cases higher echogenicity compared to the echogenicity of the endometrium. Large polyps may appear as a full area of endometrial thickening, which are difficult to differentiate from simple hyperplasia. Polyps are easy to diagnose 

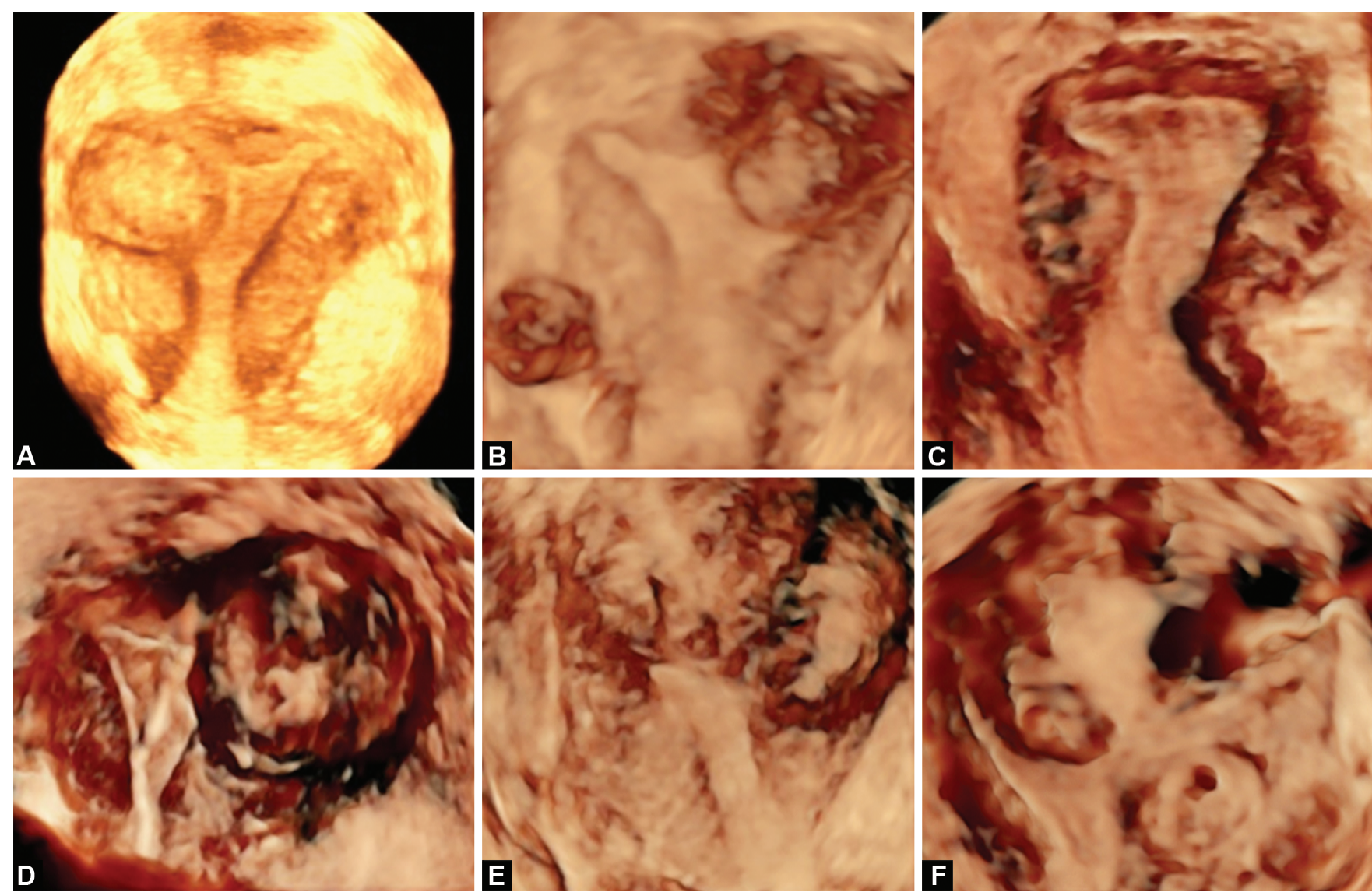

Figs 4A to F: The 3D ultrasound of FIGO classification: types I, II, and III: (A to D); Distortion of uterine cavity by myomas (E and F); Uterus myomatosus. ESGE classification: Type I: $<50 \%$ myometrial extension (A and B); Type II: >50\% myometrial extension (C and D)

during periovulatory phase of the menstrual cycle. Helpful sign to diagnose endometrial polyp is the "interrupted mucosa", which is when the highly echogenic linear interface where the opposing endometrial mucosal surfaces coapt can be followed to a point at which it is focally interrupted. ${ }^{6}$ Color Doppler sign is the presence of a "single feeding vessel" of endometrial polyp. In cases where there is a group of small polyps, ${ }^{7} 3 \mathrm{D}, 2 \mathrm{D}$, or $3 \mathrm{D}$ saline infusion sonohysterography (SIS) US examination, which uses static acquisition, or direct mode during SIS, will allow the actual position and quantity of the lesion to be clearly visualized (Figs 9 and 10). During evaluation of the endometrial polyp, it is important to detect the very rare group named adenomyoma, i.e., atypical polyploidy adenoma, or endometrial-type adenomyoma, which can mimic malignancy potential ${ }^{8}$ (Fig. 11).

\section{Adenomyosis}

Adenomyosis by definition is a gynecological disorder characterized by the presence of ectopic endometrial glands and stroma (connective tissue) within the myometrium, with smooth muscle hyperplasia and hypertrophy. In the past, the age of women diagnosed with adenomyosis was between 40 years and 50 years and was diagnosed based on hysterectomy specimens. ${ }^{9}$ Currently, the definitive diagnosis is more commonly made by hysteroscopic or laparoscopic biopsy, and adenomyosis has been frequently diagnosed in women in their 20s and 30s. ${ }^{10}$ Deep infiltrating endometriosis and uterine adenomyosis have a negative impact on fertility potential of the women. The US findings can be divided into three categories, according to the histology of adenomyosis: (a) ectopic endometrial glands and stroma, (b) muscular hyperplasia/hypertrophy, and (c) increased vascularization. ${ }^{11}$ The most sensitive and specific US criteria are as follows: (1) myometrial cysts - most commonly anechoic; (2) depending on the progress of the process, the uterus is normal in size or develop diffuse globular enlargement; (3) asymmetric myometrial heterogeneity and thickening, most frequently involves the fundal region; (4) subendometrial, echogenic "linear striations" sign; and (5) regions of widening or disruption in the lateral and fundal junctional zone (JZ) in the 3D coronal plane. The combination of myometrial heterogeneity, thin shadows, and the small hyperechoic nodules and striations gives an appearance similar to the US appearance of "Swiss cheese" sign. The color Doppler ultrasound image of adenomyosis shows randomly scattered vessels or intramural signals that is distributed all over the entire surface, and absence of circular vascularization at the border of the lesion unlike at the myomas ${ }^{12-15}$ (Figs 12 to 14).

\section{Arteriovenous Malformations}

Uterine arteriovenous malformations (AVMs) can be congenital or acquired. Acquired lesions are believed to result from pelvic surgery, after unsuccessful pregnancy, curettage, cesarean delivery, pregnancy on scart on uterus from previous cesarean delivery, trophoblastic disease, neoplasm, or infection. It has been recently suggested that curettage should not be performed in a patient who presents with abnormal uterine bleeding after an abortion 

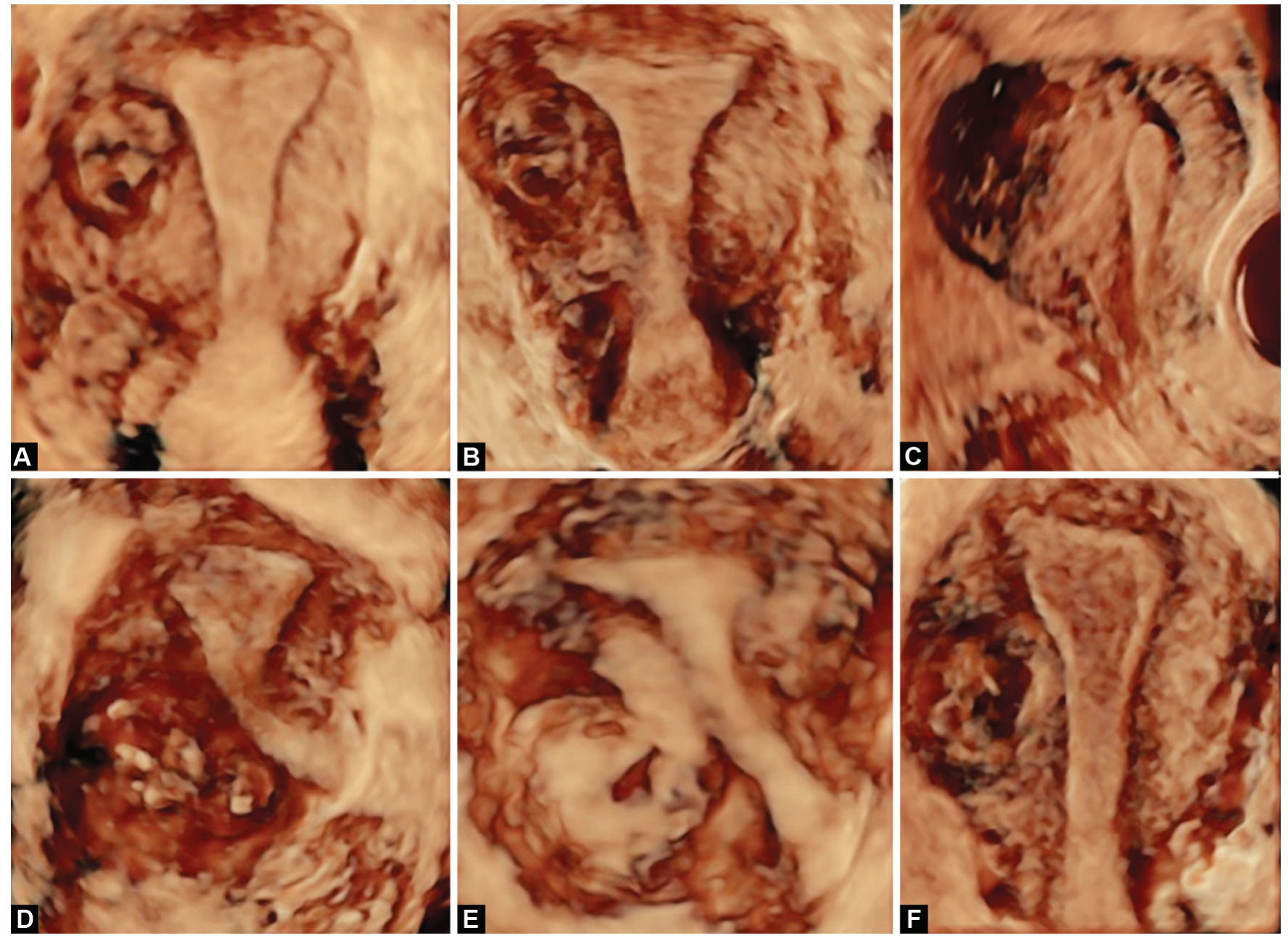

Figs 5A to F: The FIGO classification of intramural myomas: Intramural myomas with no distortion of uterine cavity even though tumor is near to EMJZ (FIGO type III), (A to C): Intramural myoma localized on posterior wall, FIGO type IV: 100\% intramural myoma with no distortion of uterine cavity (E and F)
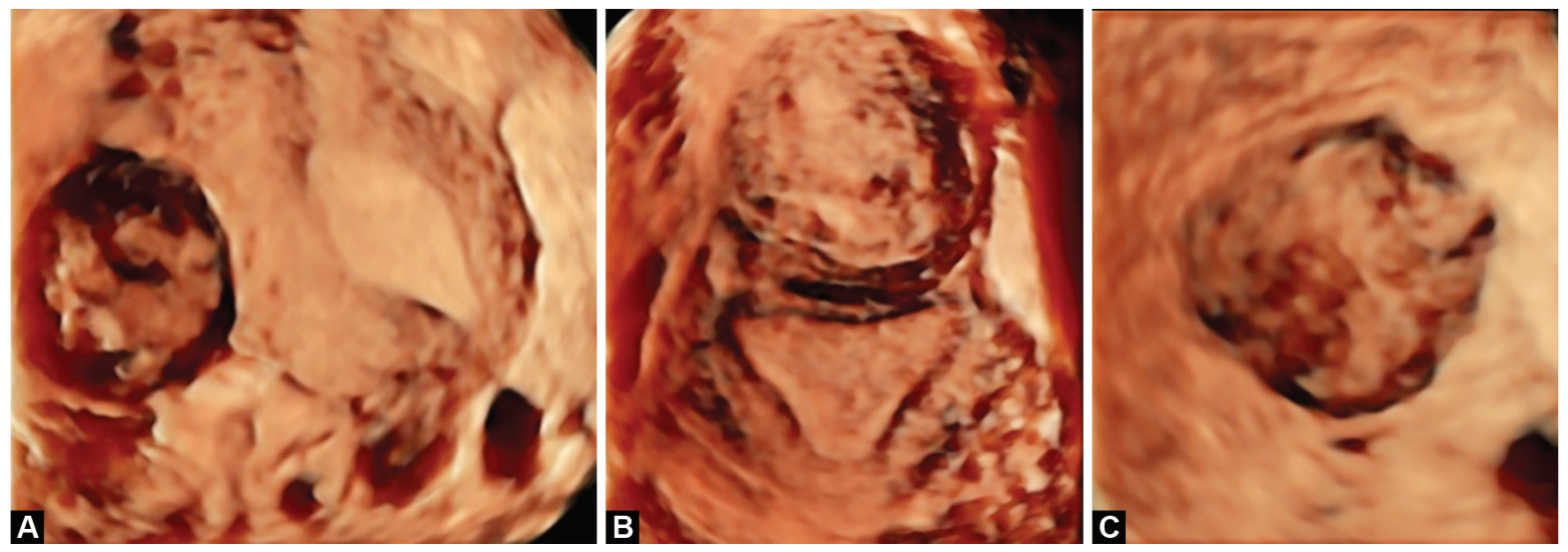

Figs $6 \mathrm{~A}$ to $\mathrm{C}$ : The 3D ultrasound: Subserous myoma (A and B) free myoma (C). FIGO: types VI and VII

or a delivery when there is a US detected hypervascular area with turbulent flow within the myometrium. The 2D sonography has a limited role in the diagnosis of uterine AVMs and often shows an ill-defined uterine mass consisting of mildly echogenic tissue that is interspersed with multiple small hypoechoic spaces of varying sizes. The color Doppler sonography is the preferred method of diagnosing uterine AVMs. On color Doppler US, a uterine AVM appears as a hypervascular lesion with turbulent flow within 

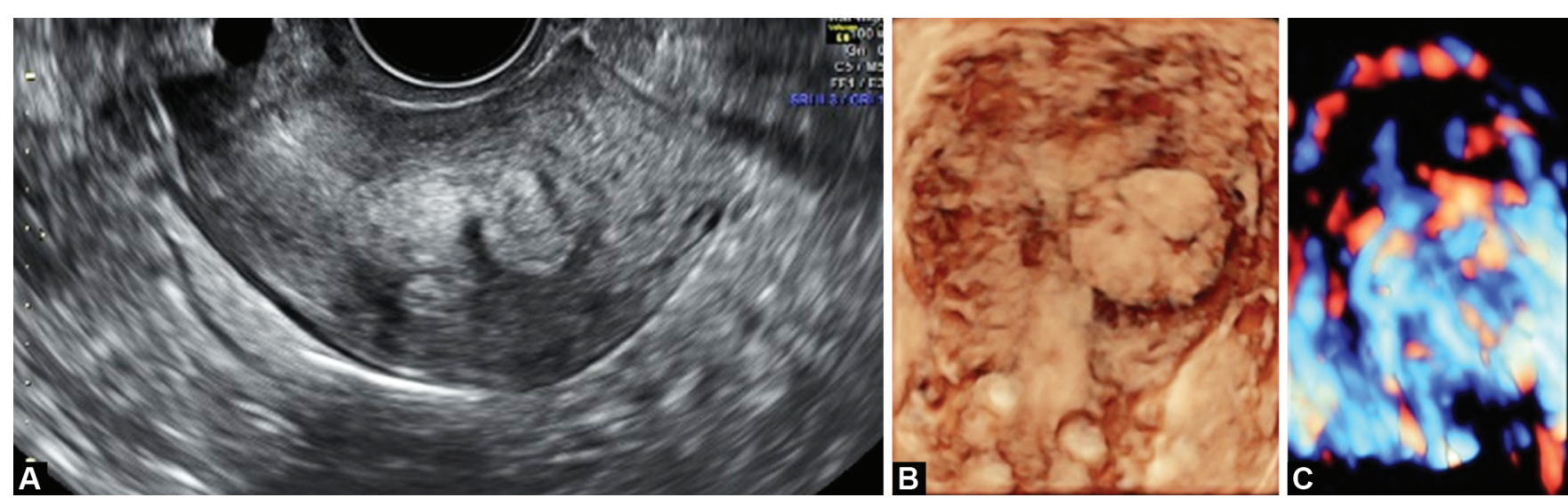

Figs 7A to C: The 3D ultrasound: Uterine angioma, very rare conditions, note the specific pattern which is different from myometrium and rich vascularization of the tumor
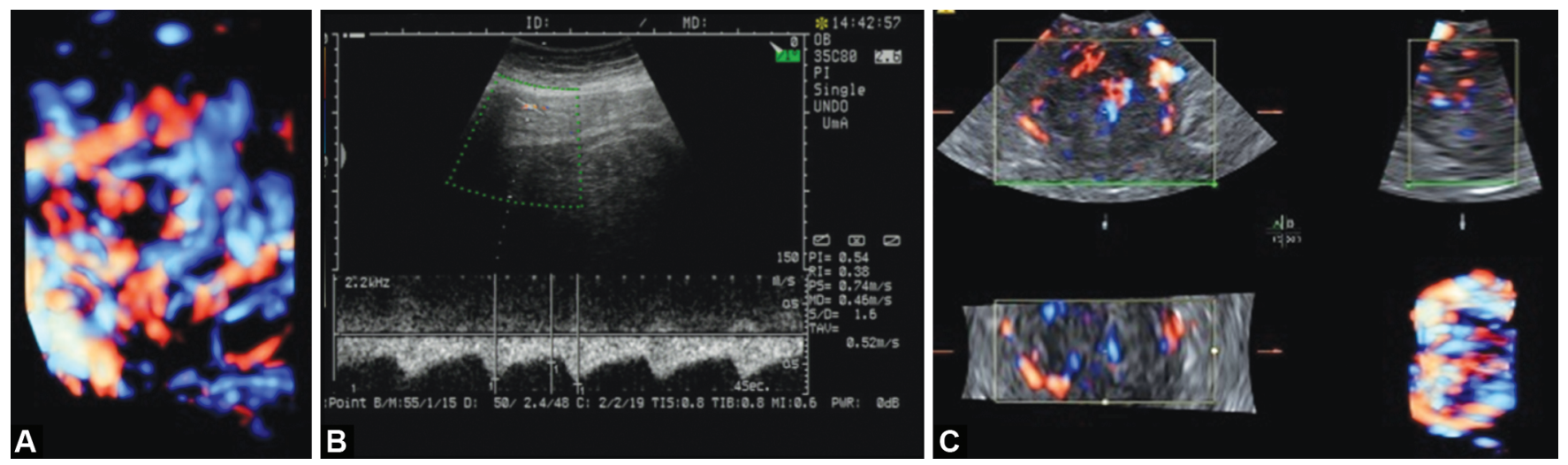

Figs. 8A to C: Uterine sarcoma (larger in diameter, with unclear borders from the surrounding tissue and high vascularization in the center of the tumor)
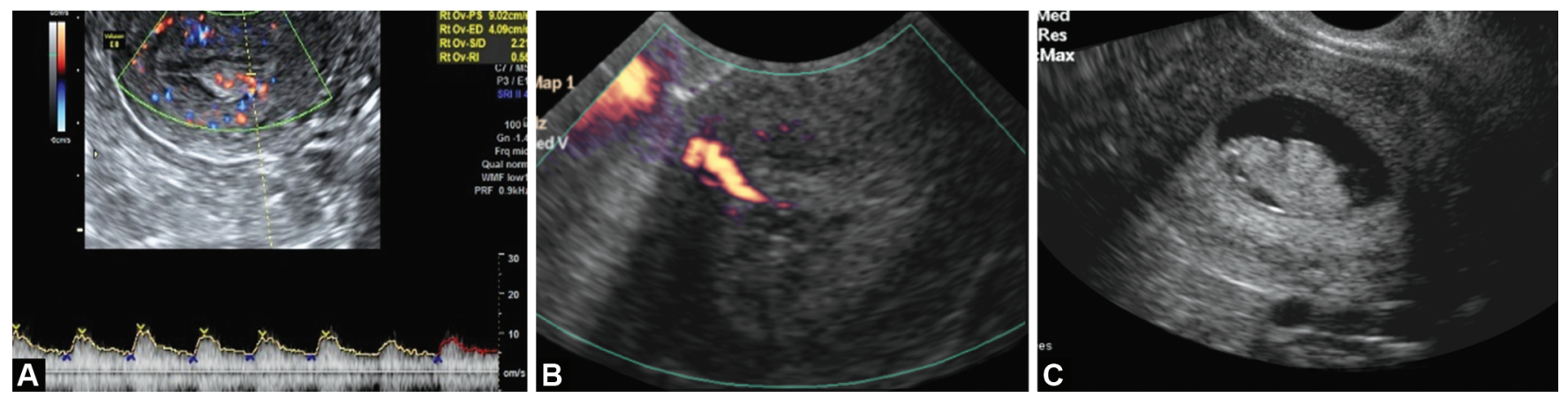

Figs 9A to C: Endometrial polyp: (A) "Interrupted mucosa” sign in a hypoechoic endometrium; (B) "Single feeding vessel” sign of the polyp; (C) SIS shows clearly the contour of the endometrial polyp

the myometrium. The AVMs can be distinguished from these pregnancy-related conditions using serum human chorionic gonadotropin measurement ${ }^{16,17}$ (Fig. 15).

\section{ISTHMOCELE}

Isthmocele is a myometrial defect resembling a pouch on the anterior wall of the uterine isthmus, over a previous cesarean scar. The prevalence of isthmocele ranges from 24 to $70 \%$ in women with one or more previous SC. These radiology or US findings can be found incidentally in the absence of symptoms or be associated with clinical symptoms. Therefore, they can also be classified as asymptomatic or symptomatic when presenting abnormal uterine bleeding, pelvic pain, and infertility. Transvaginal US (TVUS) is the initial and most usual method described to assess the integrity of the uterus wall in nonpregnant patients. The defect has been observed on TVUS as an anechoic triangle in the myometrium with the base communicating to the uterine cavity, or a deformity (wedge shaped, concavity or sacculation) on the anterior isthmus. ${ }^{18}$ Some authors classified the findings according to the size of the defect: a large defect is described as a myometrial reduction of $>50 \%$ of the wall thickness or even $>80 \%$ by some authors. ${ }^{19}$ For management purposes, Marotta et al. ${ }^{20}$ adopted the cutoff of RM $>3 \mathrm{~mm}$ as a large defect and an myometrial reduction (RM) $\leq 3 \mathrm{~mm}$ as a small defect (Fig. 16). 

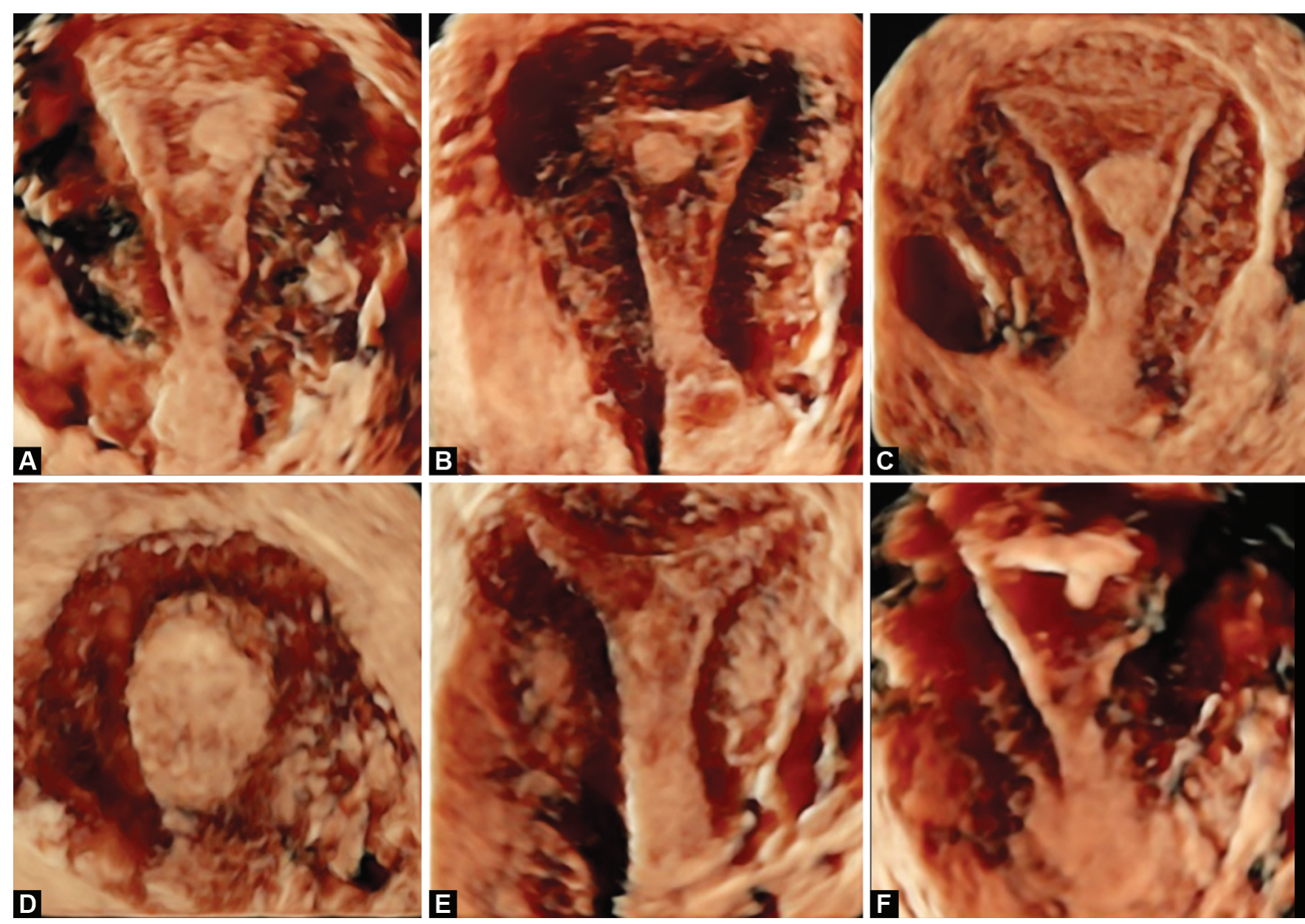

Figs 10A to F: Endometrial polyps: (A) Polyposis; (B) Endometrial polyp at the upper part of uterine cavity; (C) In the lower third; (D) High polyp reaching more than two third of the uterine cavity; (E) Polyp in the middle of the uterine cavity; (F) Small fundal polyp detected during menstrual bleeding
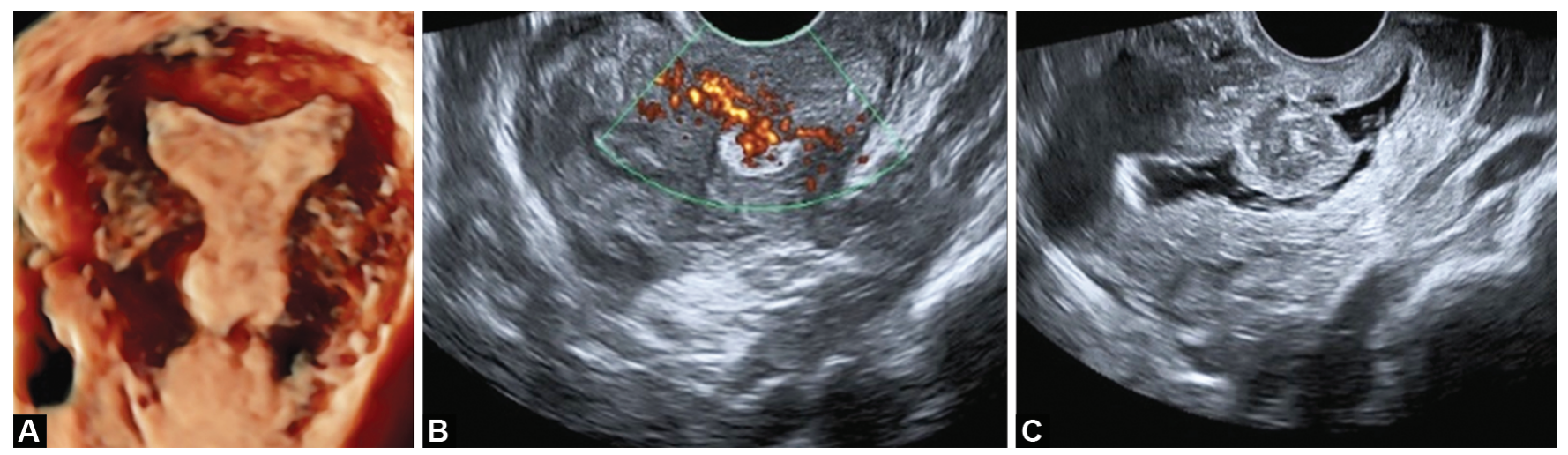

Figs $11 \mathrm{~A}$ to C: Polyploid adenoma usually is located at the isthmic part of uterine cavity and have same degree of atypia ( note the rich vascularization compared to endometrial polyp) (A to C). SIS detected the volume of polyploid adenoma

\section{Intrauterine Adhesions or Asherman's SYNDROME}

Intrauterine adhesion is also known as intrauterine synechiae, uterine atresia, or endometrial sclerosis. The most common presentation of Asherman's syndrome is secondary infertility. These patients have higher risk of recurrent miscarriages, second trimester loss, preterm delivery, incompetent cervix, uterine rupture, and placenta accreta. The TVUS is useful in measuring the thickness of the endometrial lining with or without sonohysterography (injection of sterile saline into the uterine cavity), which can show the adhesions that characteristically appear as "bridging bands" of tissue that distort the cavity. The bands may vary in thickness, but their echogenicity is usually the same as the echogenicity of the adjacent myometrium. One of the typical US finding is the presence of hypoechoic areas with interruptions in the endometrial 

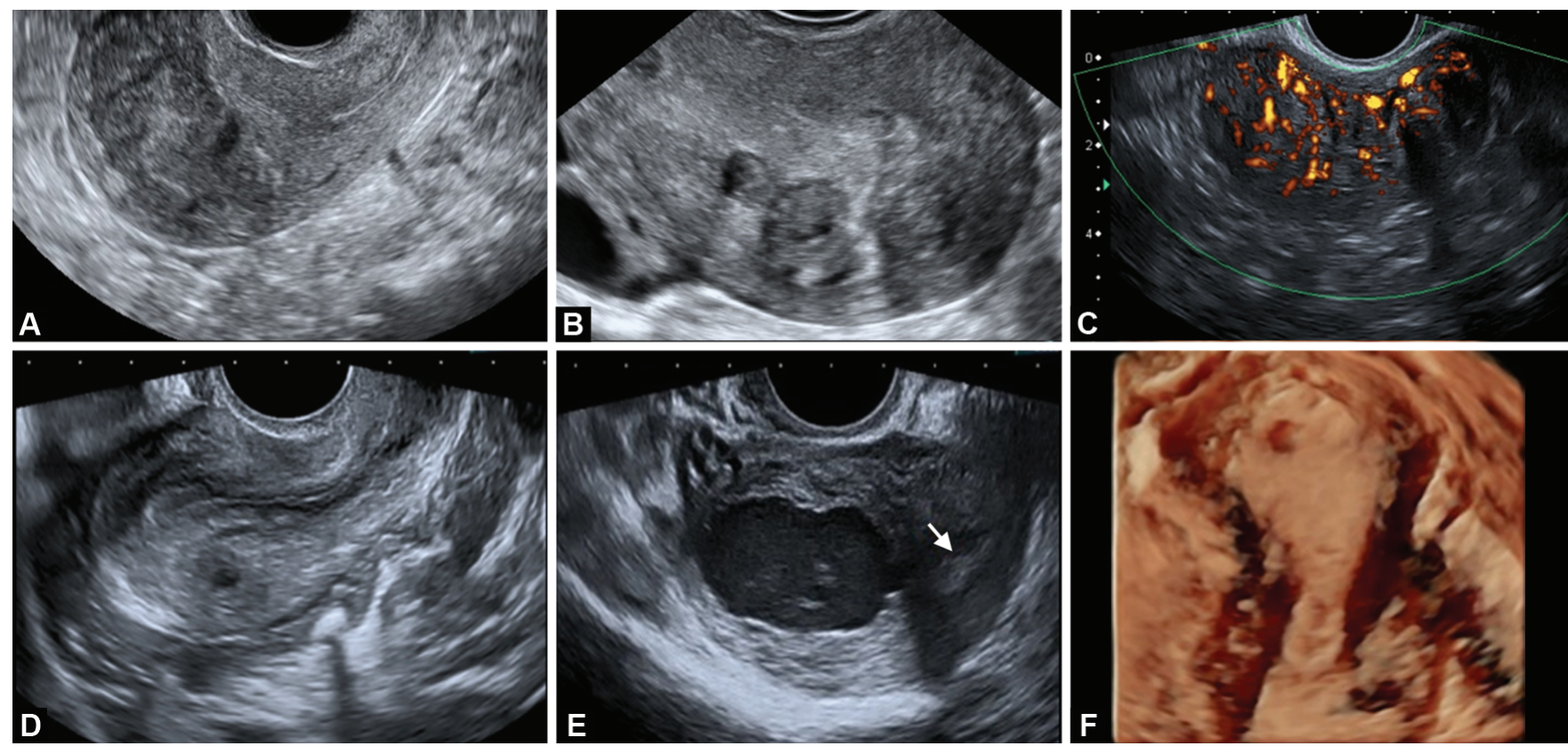

Figs $12 \mathrm{~A}$ to F: The most common ultrasound findings in adenomyosis: poorly marginated hypoechogenic and heterogeneous areas, "Swiss cheese" sign ( $A$ and $B$ ) absence of circular vascularization at the border of the lesion $(C)$, myometrial cysts $(D$ to $F)$
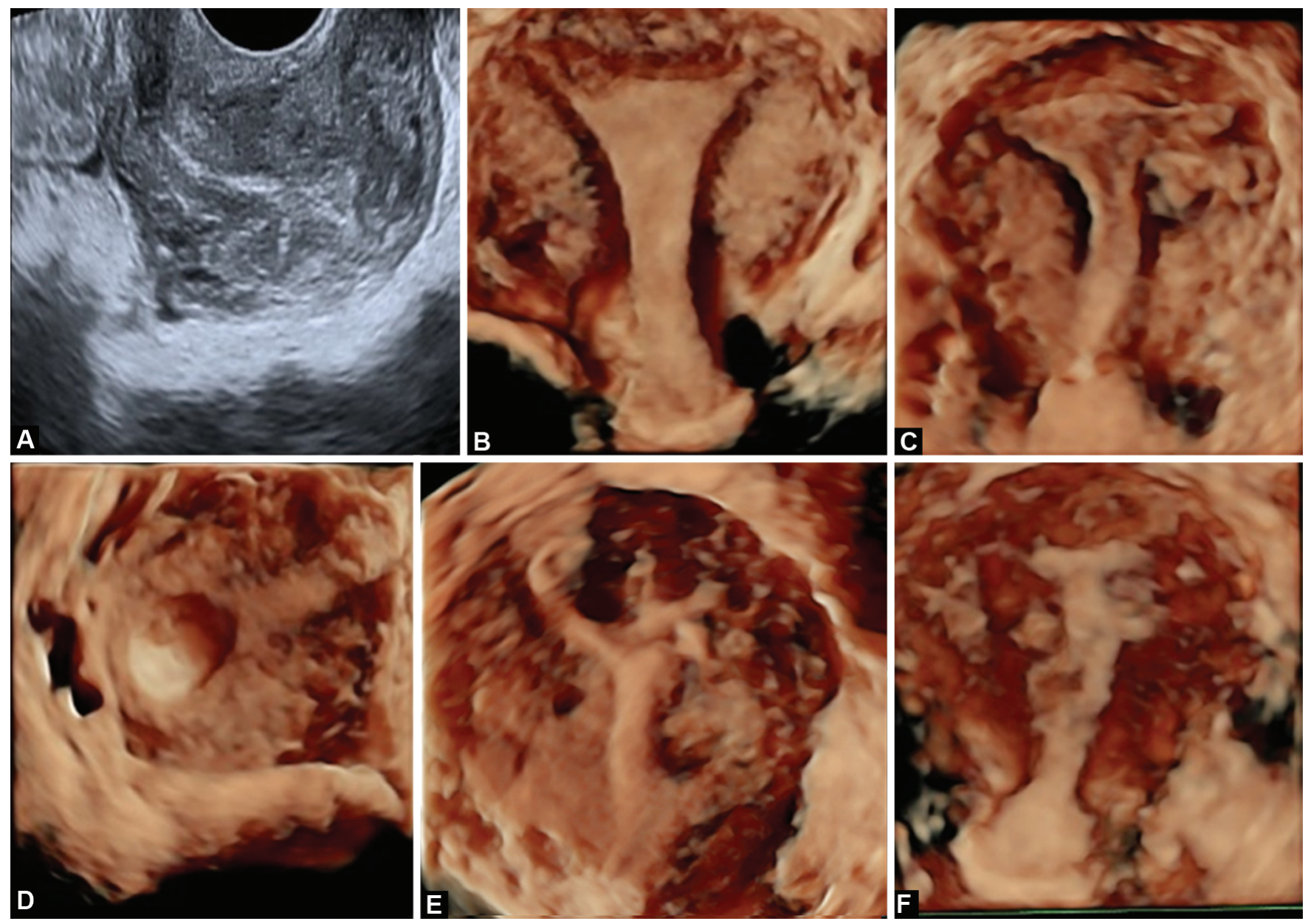

Figs 13A to F: The 2D/3D vaginal ultrasound shows irregular and disrupted MEJZ: (A) "Linear striations" sign; (B and C) 3D-small infiltration at the fundus and lateral wall of early adenomyosis; (D) Protrusions of the cyst into the junctional zone; (E and F) High area of disrupted JZ by a severe adenomyosis 

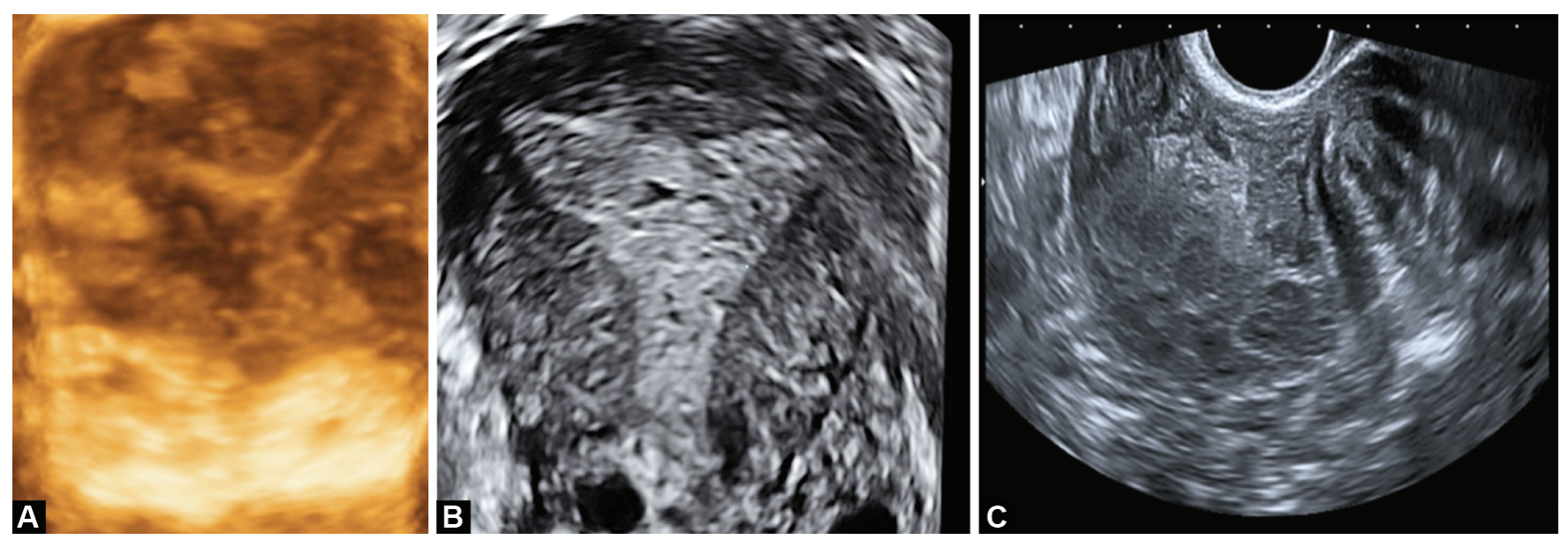

Figs 14A to C: Differential diagnosis between: (A) Adenomyosis; (B) Glandular hyperplasia; (C) Myoma uteri
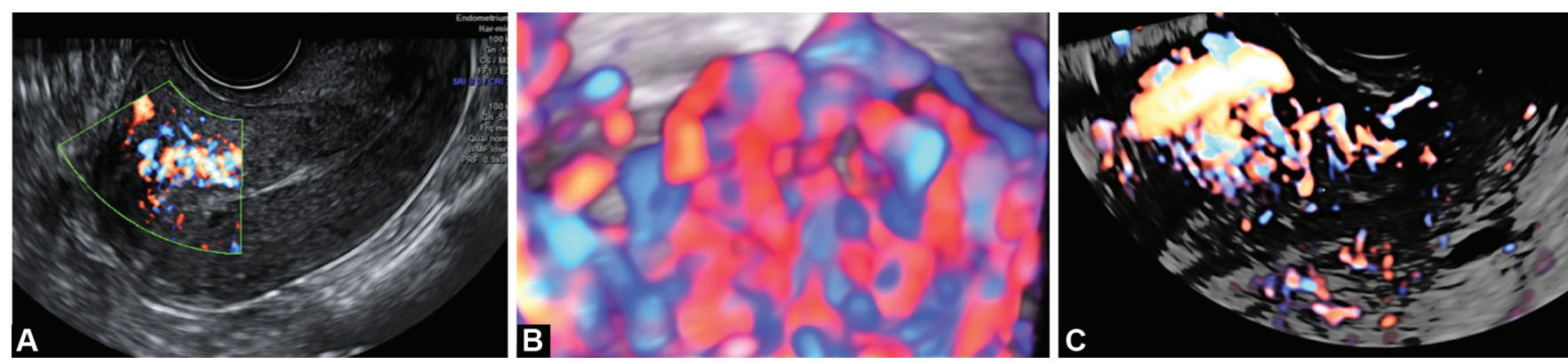

Figs 15A to C: Uterine AVMs: (A) Color and/or power Doppler is a significant marker for the site of the pathologic blood vessels; (B) Torturous vessel; (C) Sign of "vascular lake"
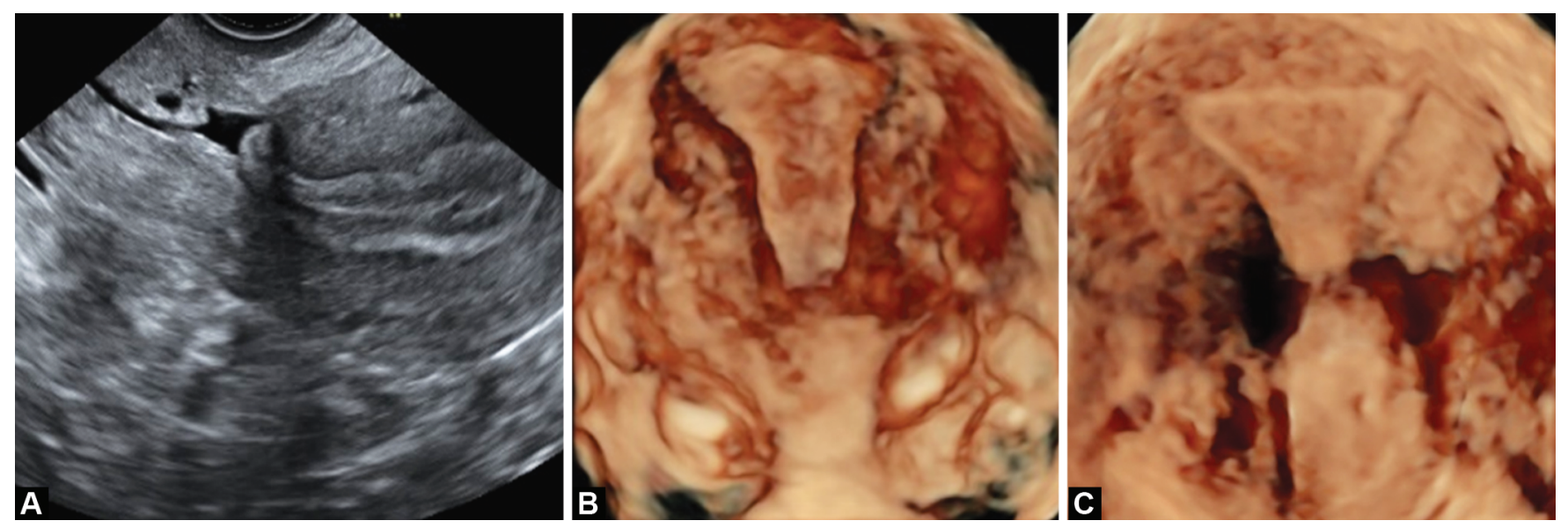

Figs $16 \mathrm{~A}$ to C: Isthmocele: Triangular-shaped defect detected of 2D and 3D ultrasound

layer (skip lesions representing entrapped menstrual blood or secretions from preserved functioning endometrium); and obliteration of the uterine cavity can be focal, partial or complete. In cases with significant intrauterine adhesions, the most common feature that that can be found is thin atrophic endometrium that is unresponsive to estrogens. The 3D US scanning can provide the clinicians with information that are detailed and self-explanatory with data regarding the location and extent of cavity obliteration and obstruction ${ }^{21}$ (Fig. 17).

\section{ENDOMETRIOMA}

Endometriosis is a chronic disease affecting 10 to $15 \%$ of women in their reproductive years. It is characterized by the presence of functional endometrial glands and stroma in sites outside the uterine cavity. Ultrasound is the imaging modality of choice in the assessment of an adnexal mass, given its high accuracy in evaluating the likelihood of malignancy. A "typical" endometrioma is a unilocular cyst with a regular wall and homogeneously lowlevel echogenicity (the so-called ground glass appearance) of the 
cyst's content. ${ }^{22}$ Hyperechogenic wall foci can be seen in up to a third of endometriomas and are quite distinctive, as they are rarely found in other benign nonresolving ovarian cysts. Septations are a frequent finding in endometriomas, giving the cyst a multilocular appearance. The wall of an endometrioma is usually smooth and clearly visible, but some irregularity like a pseudopapillary projection can be present as a result of inflammation or hemorrhage. ${ }^{23}$ This situation can lead to diagnostic problems and the differential diagnosis with an ovarian malignancy can be resolved. The differential diagnosis of endometriomas includes luteal cysts, cystadenomas, pyosalpinges, dermoids, and ovarian cancers. Moreover, power Doppler can be helpful in showing the absence of flow within the cyst content when heterogeneous inner portions are found due to intracystic hemorrhage or accumulation of the dense parts of the content ${ }^{24,25}$ (Fig. 18).

\section{Chronic Pelvic Inflammatory Disease (PID)}

Around $25-35 \%$ of subfertile couples have tubal pathology, which is a cause of subfertility. Hence, it is essential to evaluate the fallopian tubes. Hysterocontrast-sonosalpingography with conventional 2D or automated 3D technology allows the physicians to evaluate tubal patency status relatively easily and also in absence of US signs for acute or chronic PID. In chronic PID, hydrosalpinx is a major pathology that is commonly found in the infertile population presented on 3D US, like visible distention of the fallopian tube due to inflammatory fluids as a result of obstruction at the fimbrial end or at the cornual end of the tubes. ${ }^{26}$ Other specific US signs include incomplete septa defined as hyperechoic septa that originate as a triangular protrusion from one of the walls but do not reach the opposite wall; and beads-on-a-string sign defined as hyperechoic mural nodules measuring about $2-3 \mathrm{~mm}$ and seen on the cross section of the fluid-filled distended structure ${ }^{27}$ (Figs 19 and 20).

\section{Uterine Anomalies}

Female uterine anomalies are common congenital benign entities with an estimating prevalence ranging from $\sim 6 \%$ in the general female population to $\sim 15 \%$ in selected patients who have recurrent pregnancy loss. Women of reproductive age during their routine examination should be examined for the presence of a potential
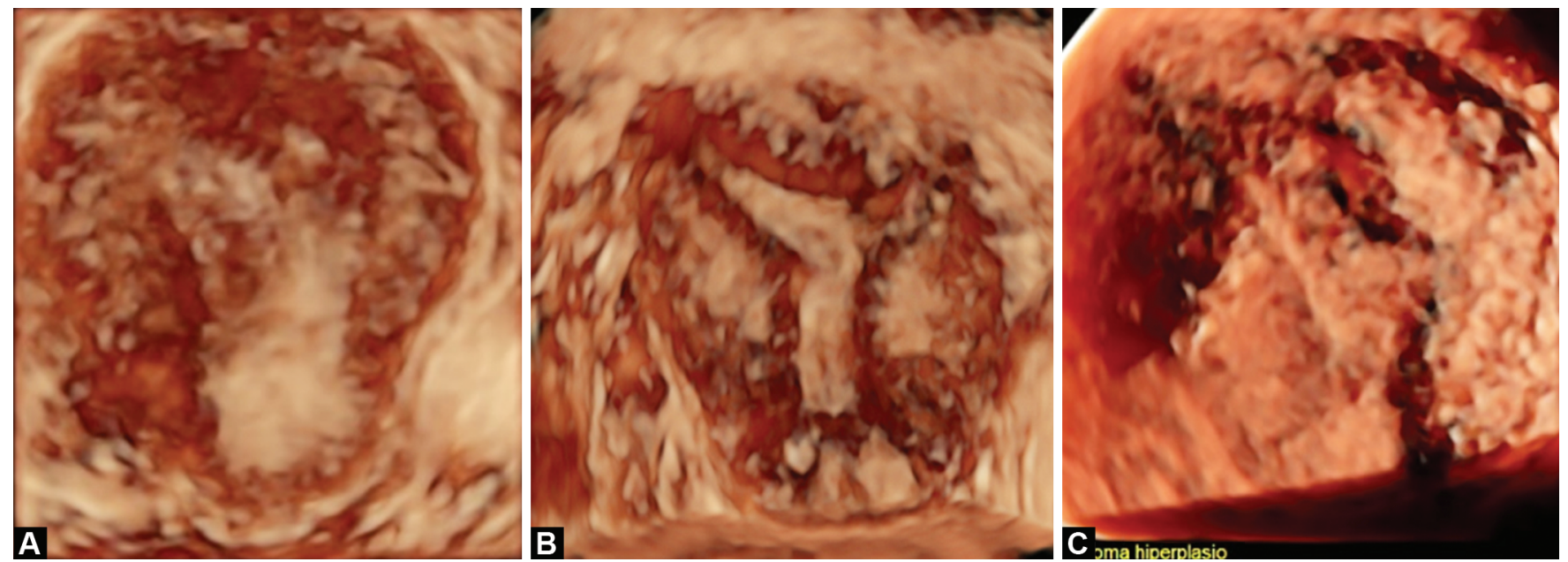

Figs 17A to C: Asherman's syndrome: 3D ultrasound image of uterus. Severity of adhesions could be expressed as an obliteration ratio (\%) $=$ obliterated area (O)/total cavity area $(C) \times 100 .{ }^{17}$
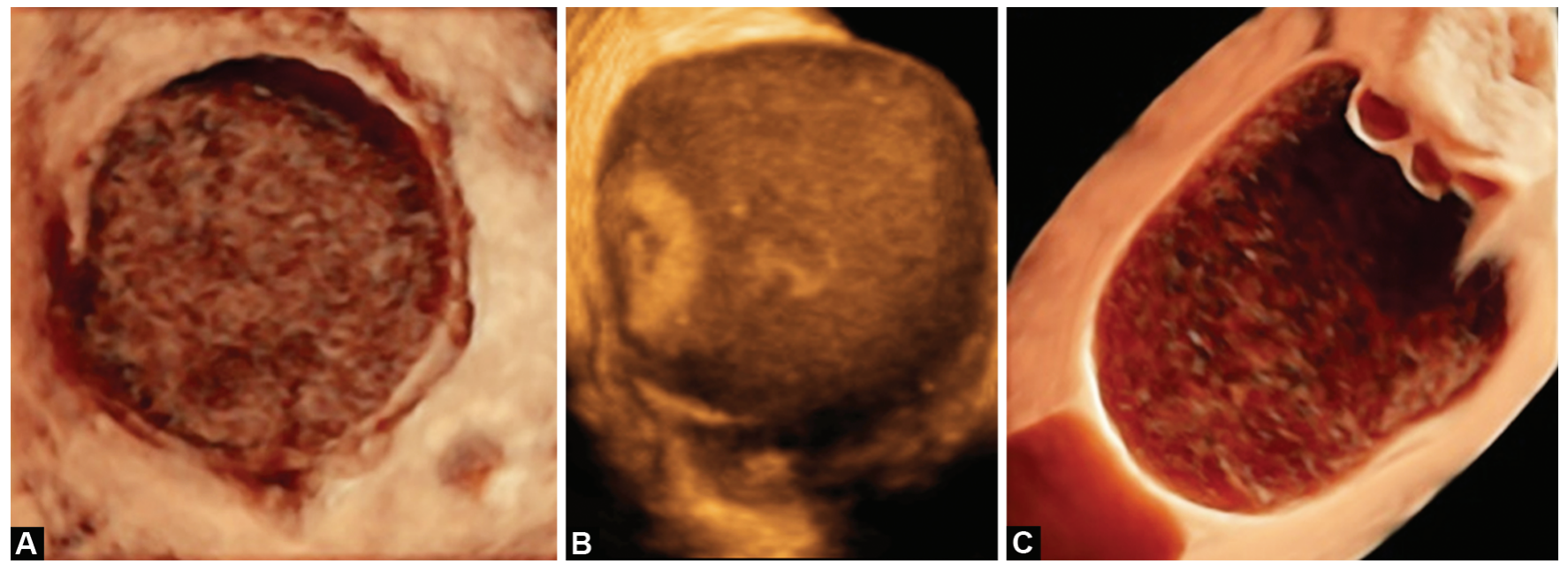

Figs 18A to C: The 3D ultrasound image of endometrioma with (A) Ground glass echogenicity; (B) Hyperechoic bulk; (C) Daughter cysts and mucinous cystadenoma as a sign of malignancy (ph: borderline mucinous cystadenoma ovaries) 

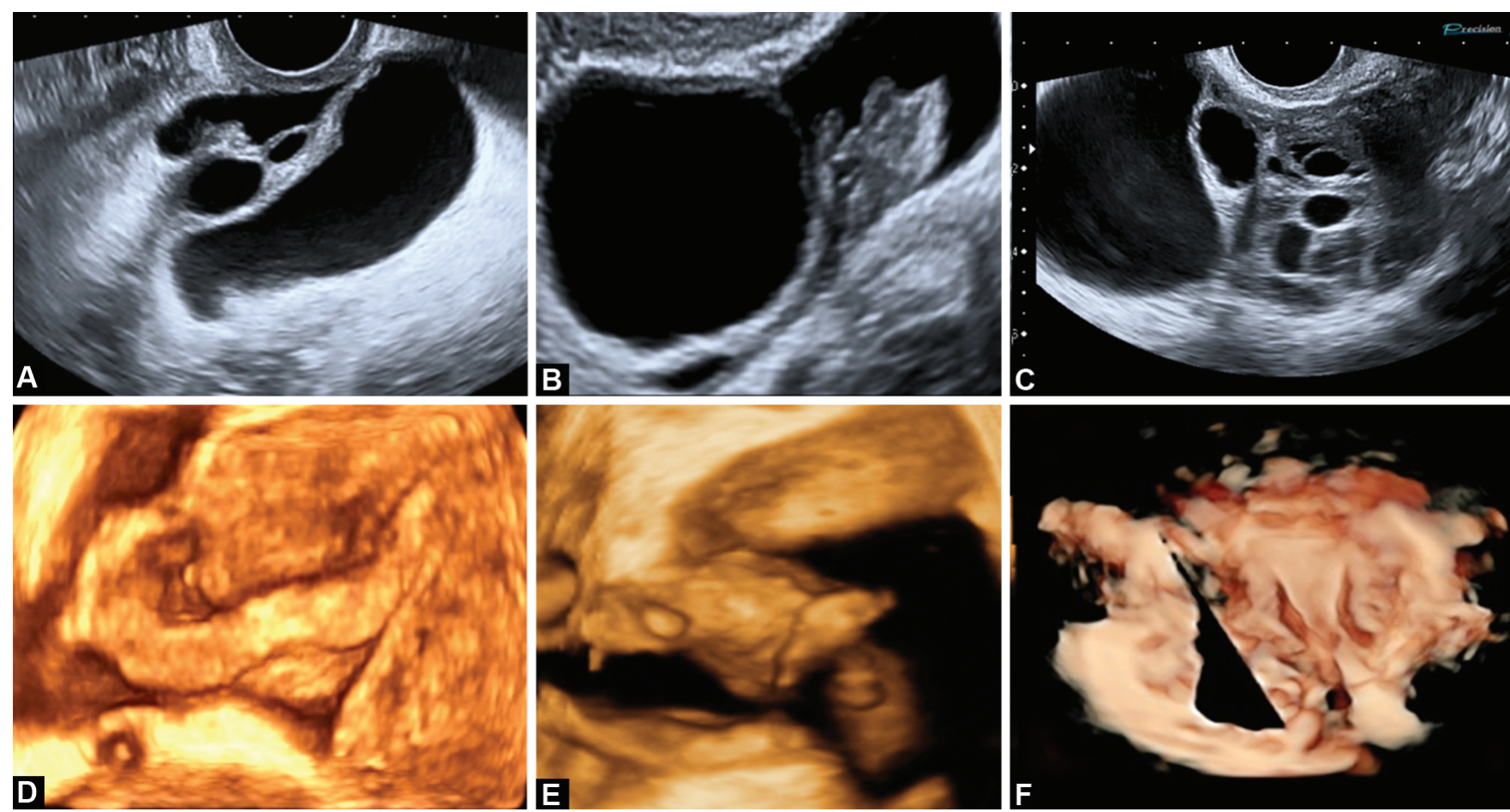

Figs 19A to F: The 2D/3D vaginal ultrasound and PID: (A) Sign of "pipe"; (B) Ciliary apparatus introverted in the inflamed tube-salpingitis; (C) Chronic hydrosalpinx: the "beads-on-a-string" sign; (D to F) 3D look of the salpingitis
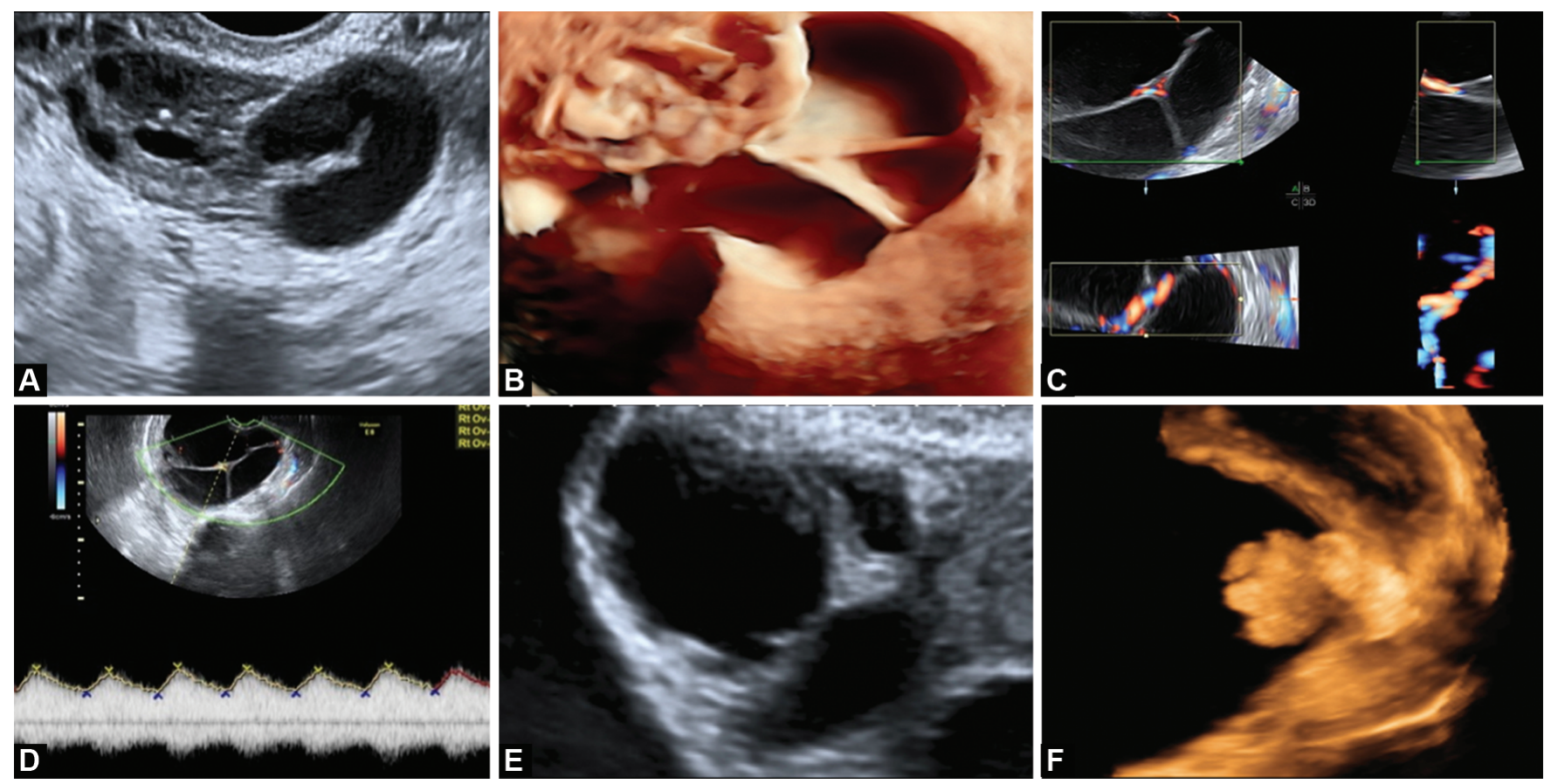

D

Figs 20A to F: (A to D) Differential diagnosis between PID and ovarian cystadenocarcinoma: pseudosepta (without contact with the opposite side of the structure, no sign of vascularization in PID) real septa = vascularized, low RI and ovarian cystadenocarcinoma; (E and F) Pseudopapillary structures in cavity distributed on the wall of the chronic inflammatory tube (beads-on-a-string) sign, different to real intraluminal papillary vegetation and ovarian cystadenocarcinoma

congenital anomaly. ${ }^{28}$ Regarding diagnosis of uterine anomalies, the $2 \mathrm{D}$ vaginal US shows limited capabilities according to the $3 \mathrm{D} / 4 \mathrm{D}$ vaginal US. Still the initial examination with $2 \mathrm{D}$ vaginal US shows some information that could be very useful. For example, sagittal plane examination will show indentation depth of hyperechogenic endometrium in the region where the cornu of the uterus is visible "sign of alligator head" and "cat-eye sign" on transversal plane. Color Doppler can show us the rich vascularization in the septum 
or the $Y$ sign that we see in the bicornuate uterus ${ }^{29}$ (Fig. 21). The $3 \mathrm{D} / 4 \mathrm{D}$ vaginal US examination in coronal plane gives us a fantastic view of the uterus and the fundal region which is very important in detecting and diagnosing the most frequent uterine anomalies like septum uteri. Uterine anomalies can be classified into many types. Now the focus is on giving better diagnosis and ways of adequate treatment, minimizing overdiagnosis and overtreatment. ${ }^{30-32}$ Septum uteri is the focus of the classification systems because it is the most frequent uterine anomaly. At this moment, the most accepted classification systems are: ESHRE/ESGE-2016, ${ }^{33}$ CUME2018, ${ }^{34}$ and ASRM-2016. ${ }^{35}$ The main difference between ESHRE/ ESGE-2016 and ASRM-2016 according to the uterus septum is that in ESHRE/ESGE-2016 classification system, the internal indentation depth is expressed in percentage, which is greater than $50 \%$ of the uterine wall thickness measured above interostial/intercornual line; while in ASRM (numeric classification), internal fundal indentation depth is $\geq 1.5 \mathrm{~cm}$, with acute angle of internal indentation, and the external fundal indentation depth $<1 \mathrm{~cm}$ is recognized like uterine septum. For the first time ESHRE and ASRM classification were compared in a study, thereby bringing different conclusions regarding the diagnosis of small uterine septum (one of the most frequent anomalies) ${ }^{32}$ (Fig. 22). While bigger anomalies like deep septum are recognized identically in the both classification systems, other group of anomalies is dysmorphic uterus according to ESHRE/ ESGE-2016 classification or "T-shape" uterus according to ASRM classification. Variations in the same anomaly should be detected properly in the aspect for need and possibility for their treatment (Figs 23 to 26).

\section{Corpus Luteum}

The formation of corpus luteum is the most important thing in the luteal phase. Ultrasound characteristic of corpus luteum is the heterogenic cystic formation and vascular changes that are similar with neovascularization characterized by a very low
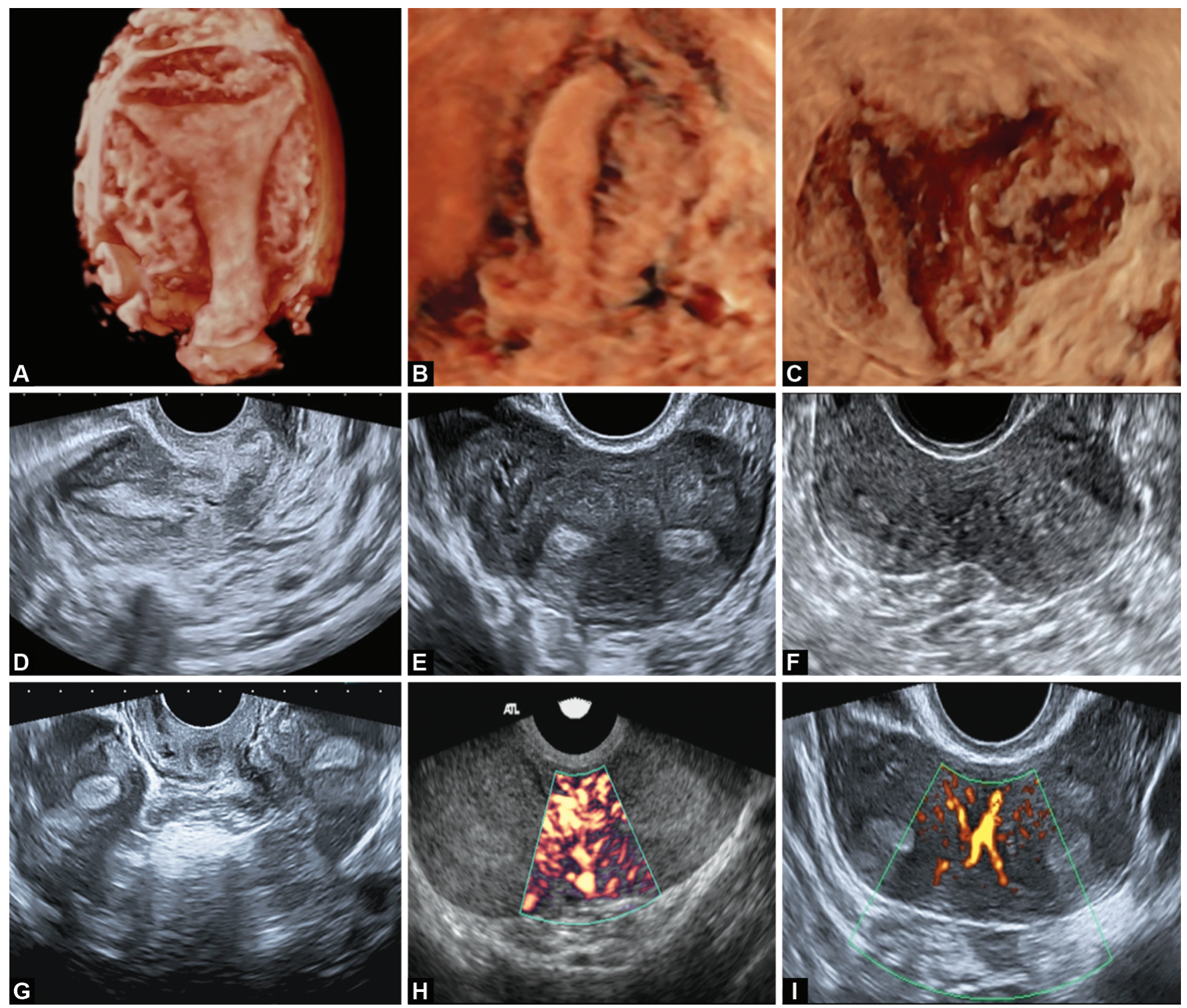

Figs 21A to I: (A) Normal uterine cavity; (B) Unicornuate uterus; (C) Unicornuate uterus with rudimentary horn; (D) 2D ultrasonography: "alligator head" sign on longitudinal section; (E) "Cat-eyes" sign on transversal section; (F) Cleft and bicornuate uterus; (G) Completely separated two bodies of uterus-didelphys uterus; $(\mathrm{H})$ Rich vascularization and uterine septum; (I) " $\mathrm{Y}$ " sings and bicornuate uterus 

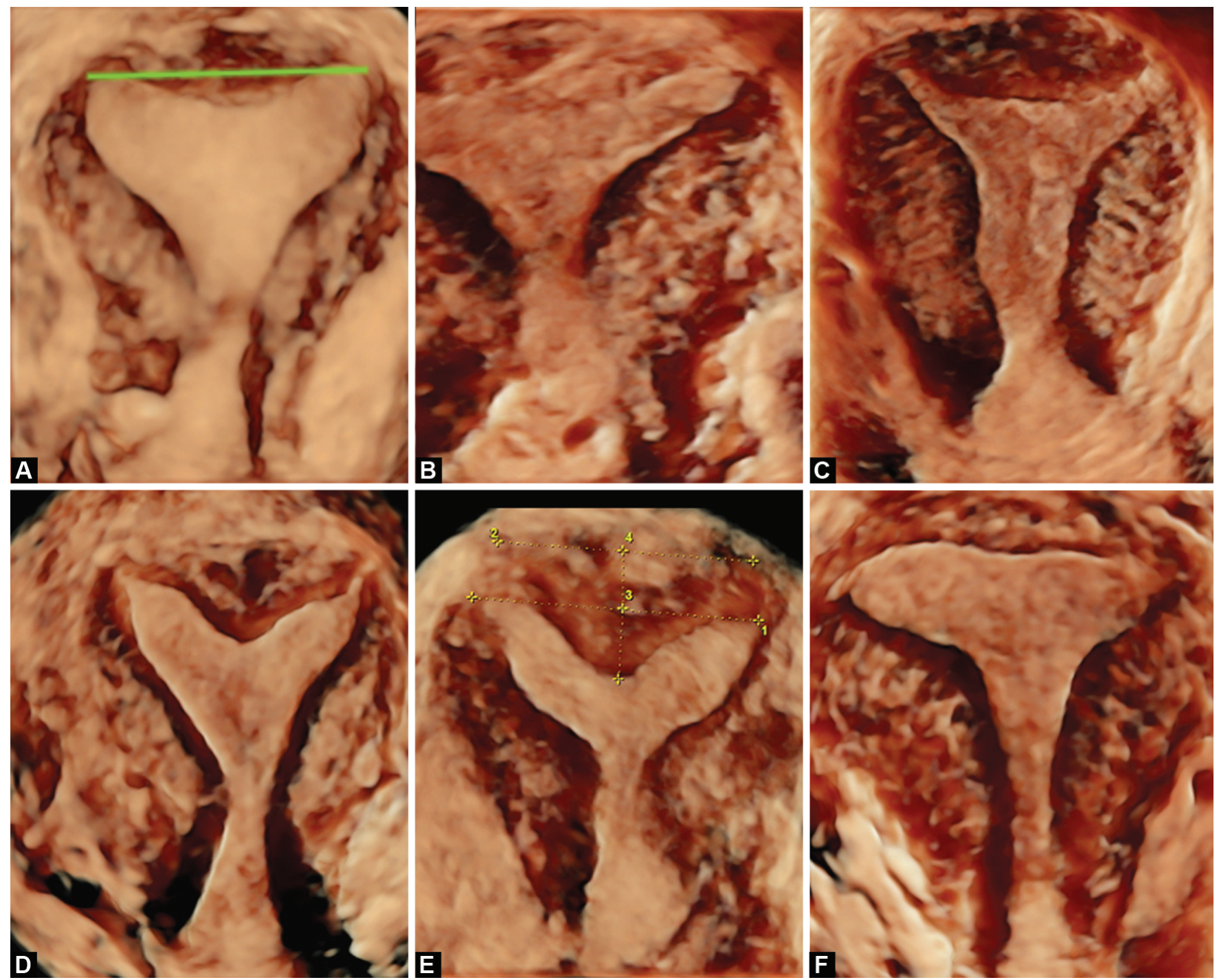

Figs 22A to F: Different classification of the most common morphological forms by ESHRE-ESGE/ASRM classification. Septate uterus by ESHRE (A to $E$ ) includes different morphological classes by ASRM: normal uterus (internal indentation $<1 \mathrm{~cm}$ ), (A to C), and arcuate uterus (D and E). Interesting cases when interostial line is clearly below the lowest point of the endometrial fundus (F)
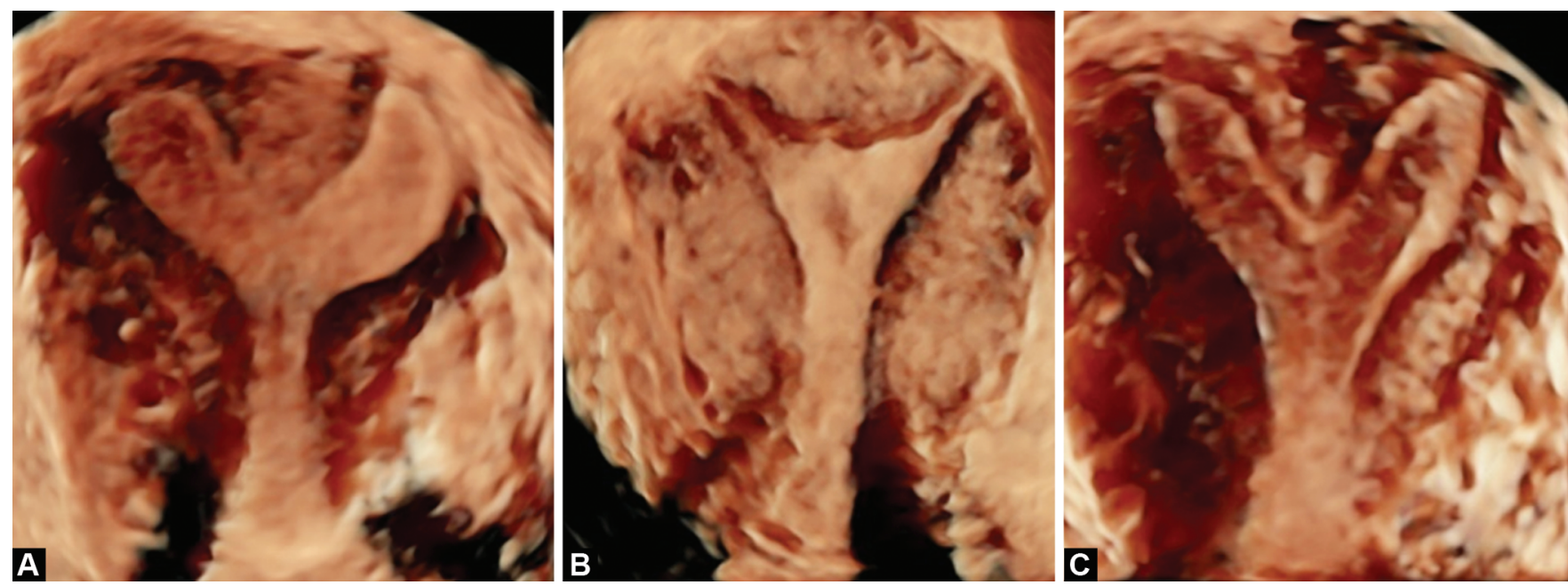

Figs 23A to C: Septate uterus:class U2A by ESHRE/ESGE classification, class VB by ASRM 

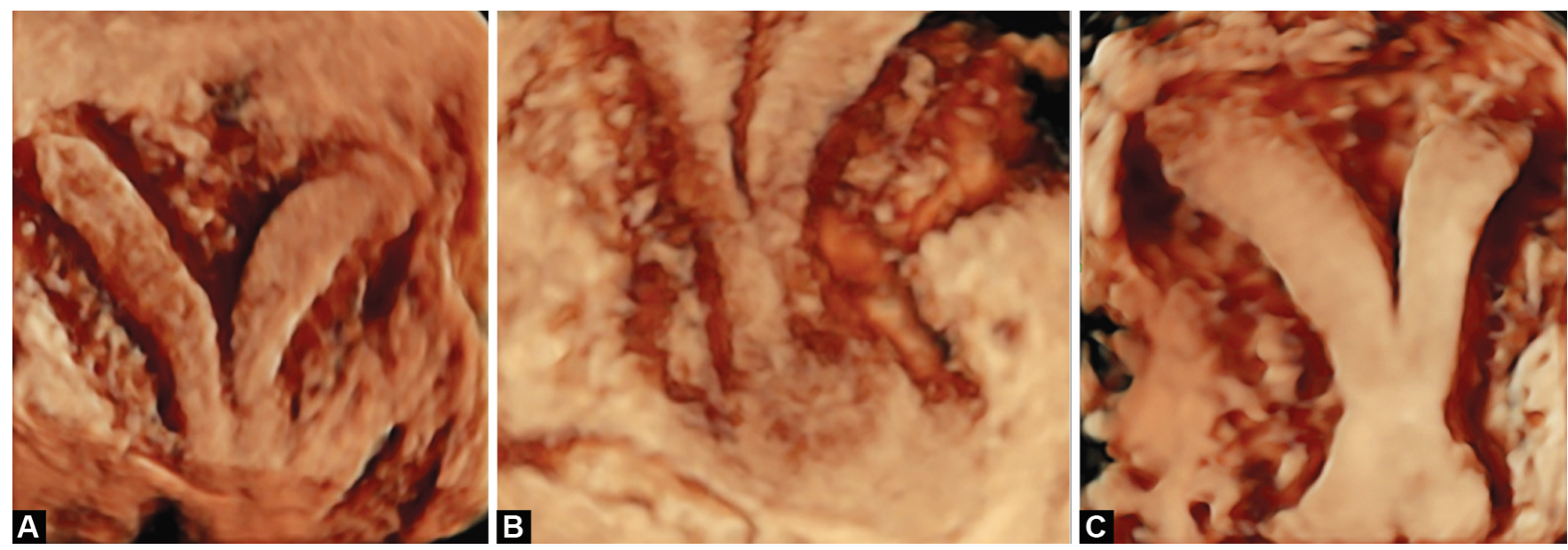

Figs 24A to C: Septate uterus: class VA ASRM, class U2B ESHRE-ESGE classification. Total division of uterine cavity and cervical canal, (A and B) division up to the internal cervical ostium (C)
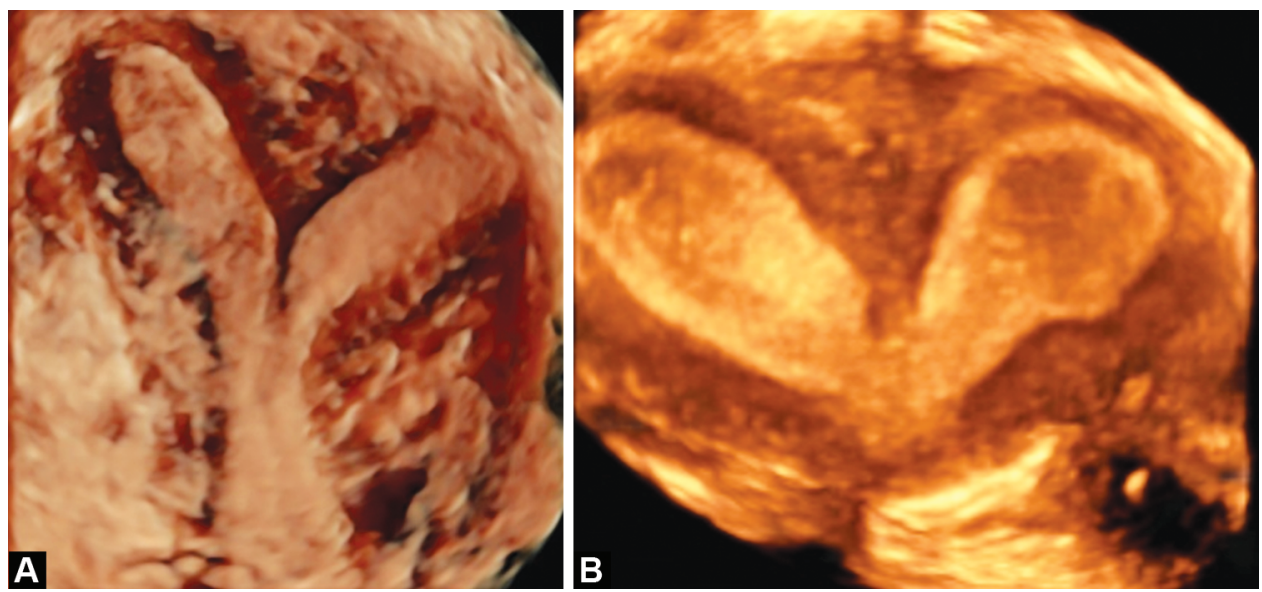

Figs 25A and B: Bicornuate uterus with residual septum: class U3C-ESHRE/ESGE, class IVB ASRM

resistivity index (RI). This can mimic certain tumor formation and that is why the US examination should be repeated immediately after the menstrual cycle 36,37 (Figs 27 and 28).

\section{Polycystic Ovaries}

With ESHRE/ASRM consensus from 2018, US definition of PCO is an ovary that is equally or more than $10 \mathrm{~cm}$ in volume and/or has equally or more than 20 antral follicles of 2-9 $\mathrm{mm}$ in diameter on either ovary, ensuring the absence of corpus luteum, cysts, or dominant follicles. ${ }^{38}$ These criteria remarkably do not fully determine a group of ovulatory, normoandrogenic hyperresponders (PCOM), with high risk of development of hyperstimulation syndrome. ${ }^{39}$ Besides, $2 \mathrm{D}$ measurements of antral follicle number (AFC), 3D vaginal US with virtual organ computer-aided analysis and sonographic automated volume calculation (SonoAVC) software can measure faster and automatically the number of antral follicles, volume of ovaries, and stromal volume. Sensitivity and specificity for the diagnosis of polycystic ovary syndrome for AFC was 85 and 94\%, respectively, and for ovarian volume (OV) (10 cc) was 81 and $84 \%$, respectively. ${ }^{40}$ Additional element is to recognize the hyperechogenic stroma and typical vascularization in PCO patients ${ }^{41}$ (Fig. 29). In PCO patients, the stromal volume, $\mathrm{OV}$, and stromal vascularization [vascularization index and vascularization flow index (VFI)] are higher. ${ }^{42}$

\section{The 2D/3D Vaginal US and Assisted Reproductive Technique (ART)}

Controlled ovarian stimulation should bring optimal number of good quality oocytes, which will later be fertilized using the IVF process. The $2 \mathrm{D} / 3 \mathrm{D}$ vaginal US is used for quantitative and qualitative monitoring of the follicles and endometrium intending to give an optimal dose of gonadotropins, timing and type of trigger for final oocyte maturation and to avoid the risk of development of hyperstimulation syndrome. The age of woman and ovarian depot are the important variables to achieve success rates in IVF. Hormonal status (anti-Müllerian hormone) and AFC before the COS start are good markers for determination of ovarian reserve. The AFC could easily be accessed with 2D/3D vaginal US. According to the number of antral follicles, the patients are categorized as low responders (fewer than 7 antral follicles), normal responders (7-11 antral follicles), and hyperresponders (over 11 antral follicles). The age of patients usually corresponds to the number of antral follicles, so patients who are older have lower number of antral follicles, but there are still a few exceptions. ${ }^{43}$ The measurement is made on two or three largest follicles in every ovary. However, clinically it is important to know the total number of follicles (over $10 \mathrm{~mm}$ ) in both ovaries to lower the risk of development of hyperstimulation syndrome. Monitoring the follicle growth can be 

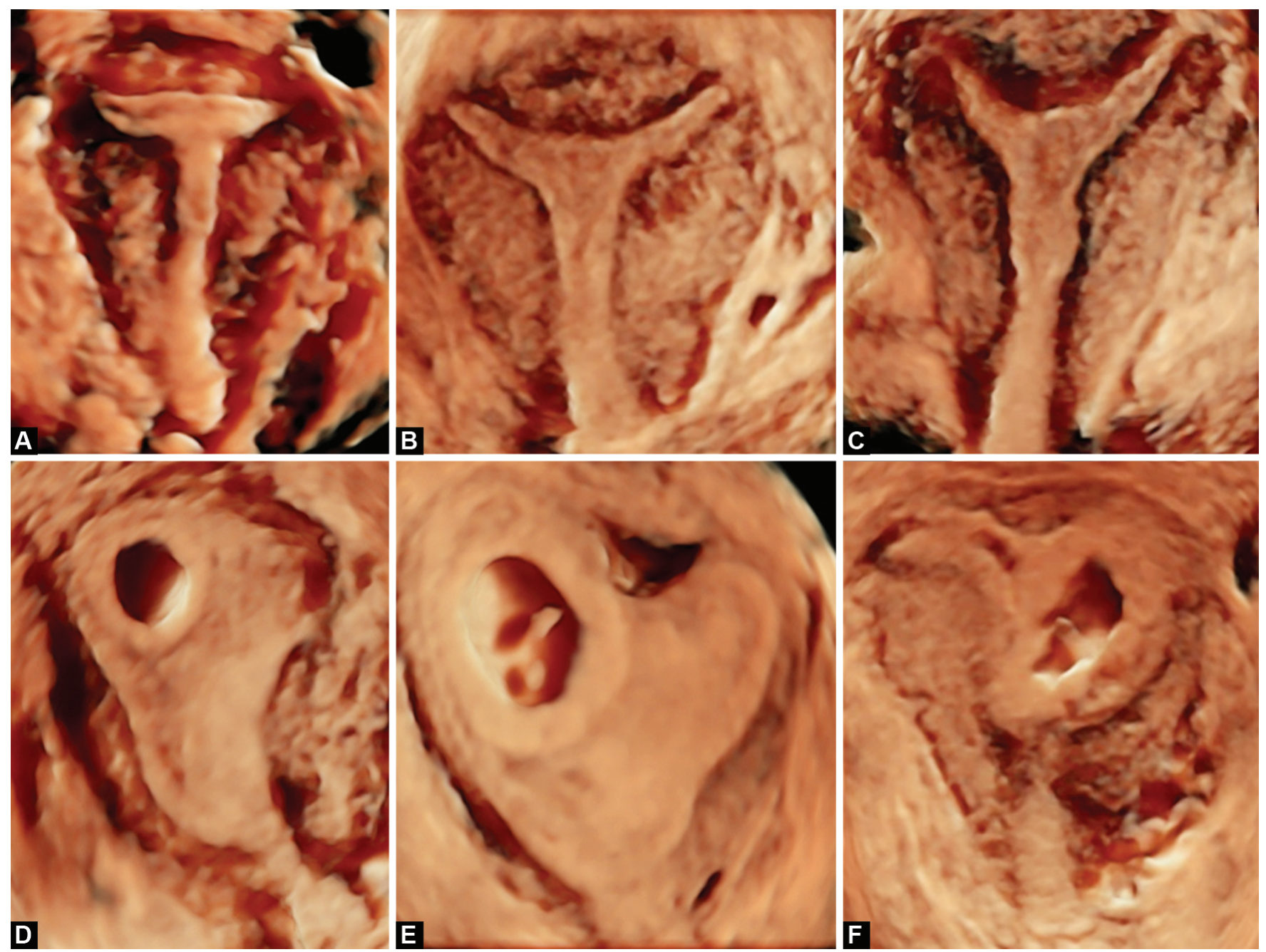

Figs 26A to F: (A) Dysmorphic uterus class U1B by ESHRE-ESGE, class VIIT-shaped uterine cavity ASRM; (B and C) internal fundal indentation >50\% of uterine wall thickness, which is frequent, is a confounding criteria for the diagnosis of dysmorphic uterus by the ESHRE-ESGE classification system; (D) Twin pregnancy and normal uterine cavity; (E) Pregnancy and arcuate uterus and (F) T-shaped uterine cavity

done with 2D vaginal US by individually measuring each follicle or with more advanced technique like 3D US to acquire the volume of the ovary; with SonoAVC by picturing color-coded follicles showing the total number of follicles in either ovary (circles); and all three diameters, mean diameter, and volume of individual follicle marked by the relevant color in the box. ${ }^{44}$ The $2 \mathrm{D} / 3 \mathrm{D}$ vaginal US is compared with the estradiol levels in patient's serum in cycles with induction of ovulation, which is important for early diagnosis of hyperstimulation syndrome. The important question is "What is the average diameter of the follicles that consist of a mature oocyte?" General assessment of follicular maturity is a follicle that is 16-18 $\mathrm{mm}$ in diameter and shows perifollicular vascularization, covering $75 \%$ of the circumference of the follicle with RI of $\leq 0.48$ and peak systolic velocity of $10 \mathrm{~cm} / \mathrm{second}$ or more is known to be functionally mature (Fig. 30), meaning even when the follicle appeared mature according to the 2D US and color and pulse Doppler parameters, the 3D power Doppler gives an important information about follicular volume, cumulus present, global assessment of the vascularization, and follicular perfusion, both qualitatively and quantitatively ${ }^{45-47}$ (Figs 30 to 32). According to our experience, examination of the follicular vascularization is commonly used in everyday practice especially when it comes to hyperresponders, where gonadotropinreleasing hormone $(\mathrm{GnRH})$ is used as a trigger for the final oocyte maturation. In few groups of patients despite the higher number of follicles (over 14-15 follicles larger than $11 \mathrm{~mm}$ ), there is no high percentage of perifollicular vascularization. In situations like this some modalities in controlled ovarian stimulation like prolongation of controlled ovarian stimulation (COS) or dual trigger can bring better result, i.e., more $\mathrm{M}$ II oocytes on the day of aspiration of follicles (Fig. 33).

\section{Uterine Receptivity and ART}

The quality of the transferred embryos and the good receptivity of the uterus are essential for a successful IVF procedure. Based on many years of measuring the endometrial thickness, endometrial morphology, and endometrial vascularization it has been understood that 2D US is accepted as a predictor of uterine receptivity and pregnancy outcome in ARTs. However, the assessment of the global vascularization of the endometrium and subendometrium and cases with no detected vascular points of spiral arteries that reach the endometrium and absence of flow in the endometrial and subendometrial zones during $\operatorname{COS}$ and 

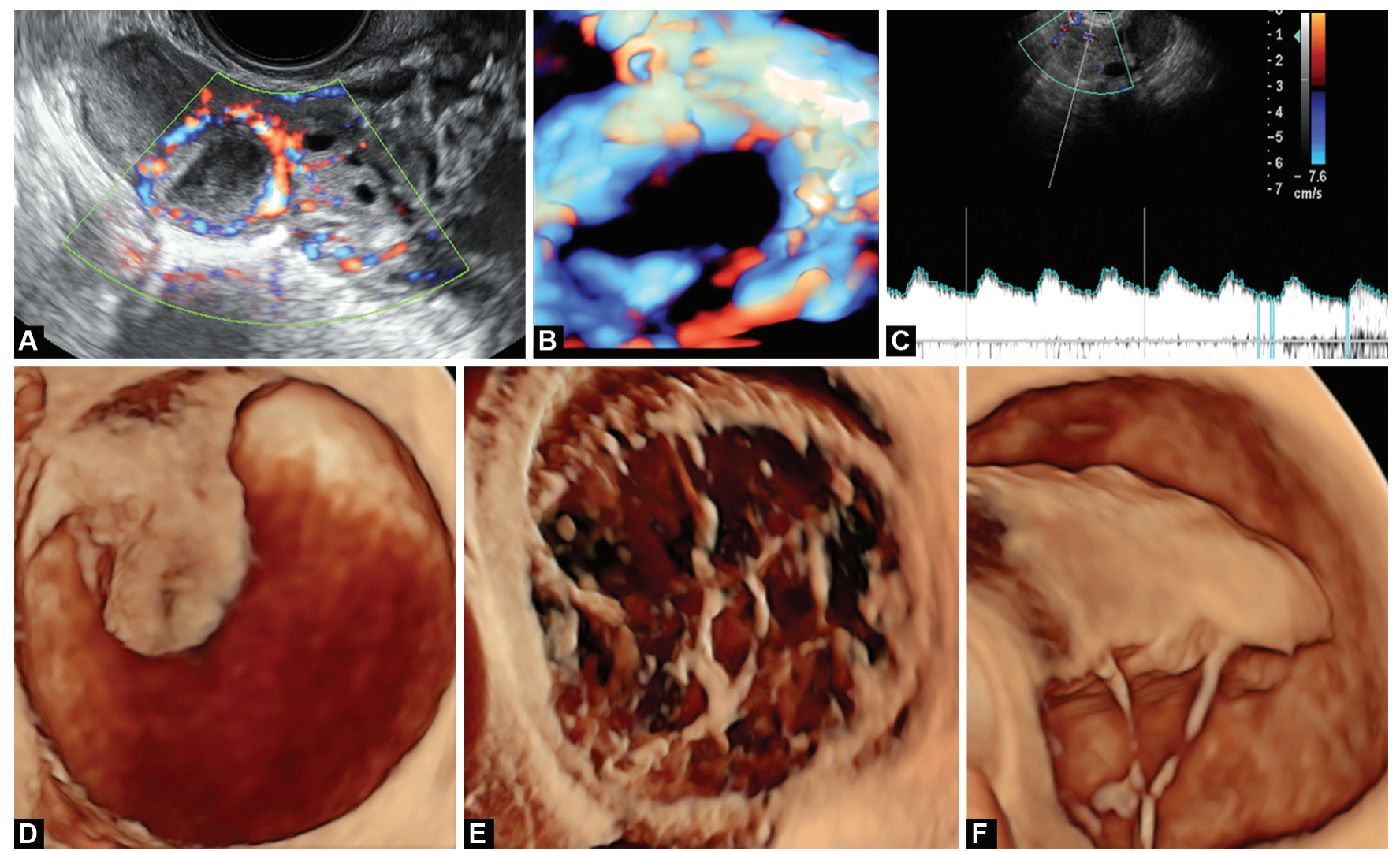

Figs 27A to F: Ultrasound characteristics of corpus luteum, vascular changes similar to neovascularization characterized by a very low resistivity index (RI) (A to C), and its heterogeneous cystic formation (D to F)
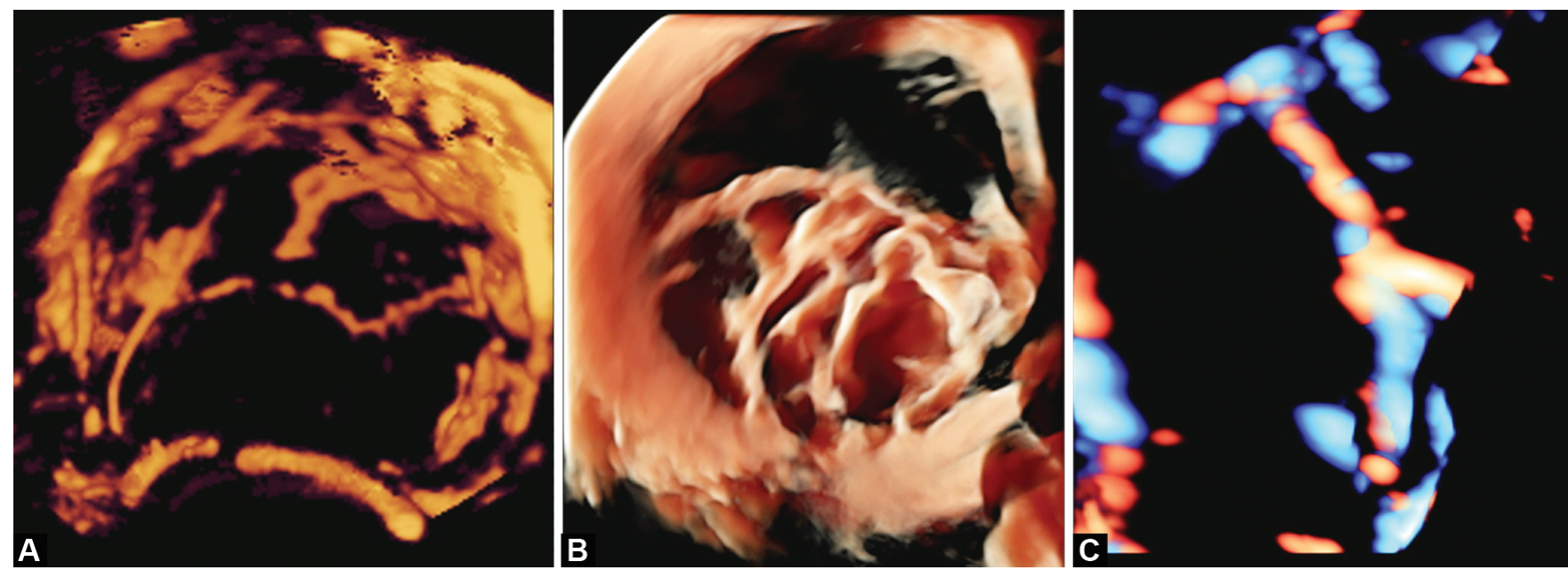

Figs $28 \mathrm{~A}$ to $\mathrm{C}$ : Differential diagnosis between corpus luteum $(\mathrm{A})$ and serous adenocarcinoma of the ovaries. (B) Intracavitary septa and corpus luteum is never vascularized and tiny, different to carcinoma septa that is thicker and vascularized (C)

ET all indicate failed implantation. The development of new US techniques brings new information about uterine receptivity. In this group of patients, the combination of endometrial thickness, endometrial morphology, subendometrial blood flow, 3D endometrial volume, 3D power Doppler with volume histogram of endometrial and subendometrial vascularization demonstrates a good sensitivity and efficiency in the assessment of endometrial receptivity. ${ }^{48,49}$ The endometrial volume
$<2 \mathrm{~mL}$ and $>8 \mathrm{~mL}$, subendometrial flow index $<11$ are strongly connected with failure of pregnancy in ART cycles. ${ }^{50}$ The other study concluded that the number of embryos replaced and the endometrial VFI (cutoff value $>0.24$ ) were the only two predictive factors for pregnancy ${ }^{51}$ (Figs 34 and 35). It is a new challenge, to examine the relation between JZ thickness on 3D US and clinical outcomes in women undergoing ART. The thickened JZ detected by magnetic resonance is associated 

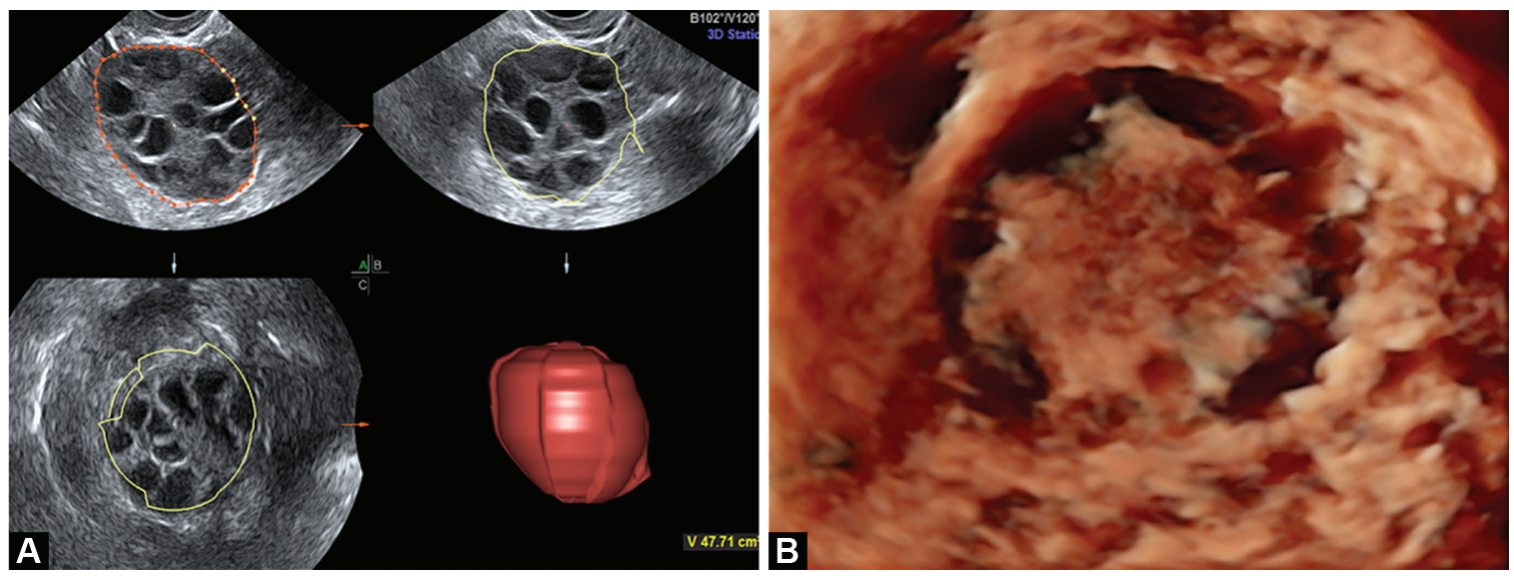

Figs 29A and B: Polycystic ovarian morphology (PCOM): Ovarian volume $>10 \mathrm{~cm}$ (A) and (B) 3D ultrasound of PCO: hyperechogenic stroma and peripherally distributed $>20$ small antral follicles
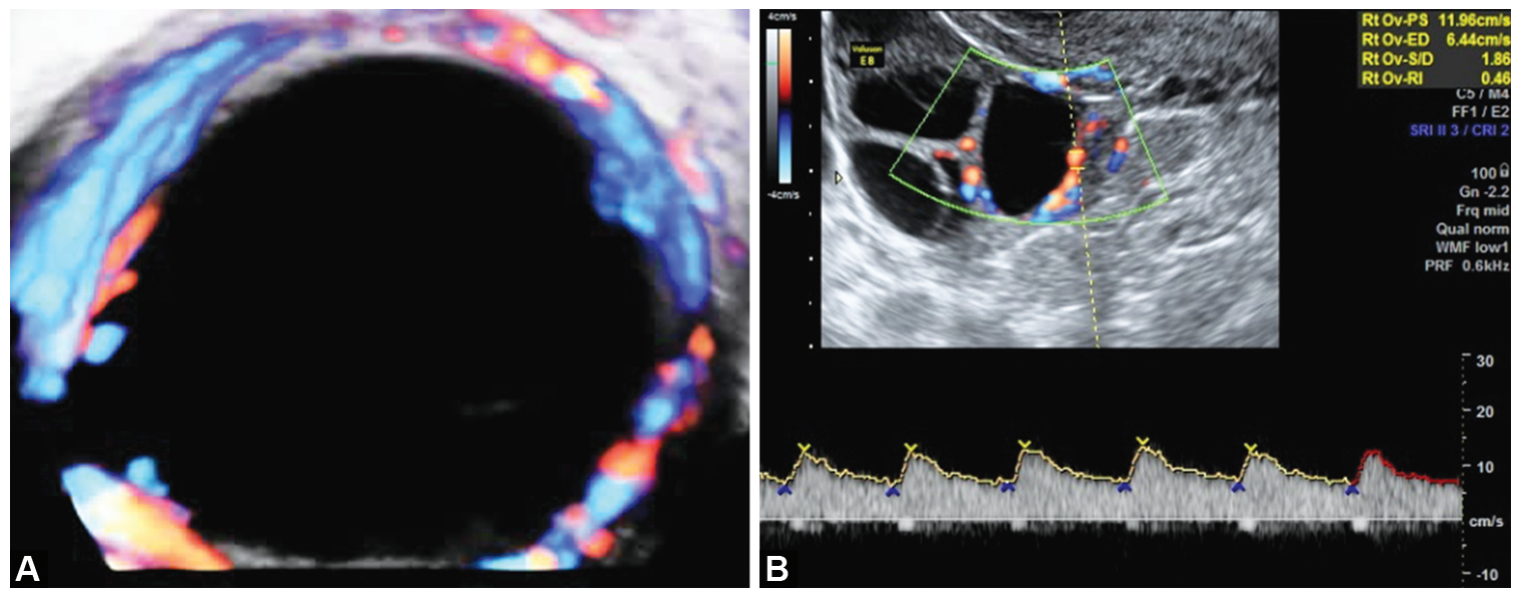

Figs $30 \mathrm{~A}$ and $\mathrm{B}$ : A follicle that is $16-18 \mathrm{~mm}$ in diameter and shows perifollicular vascularity covering $75 \%$ of the circumference of the follicle (A) with RI of $\leq 0.48$ and peak systolic velocity (PSV) of $10 \mathrm{~cm} / \mathrm{second}$ or more and it is known to be functionally mature (B)
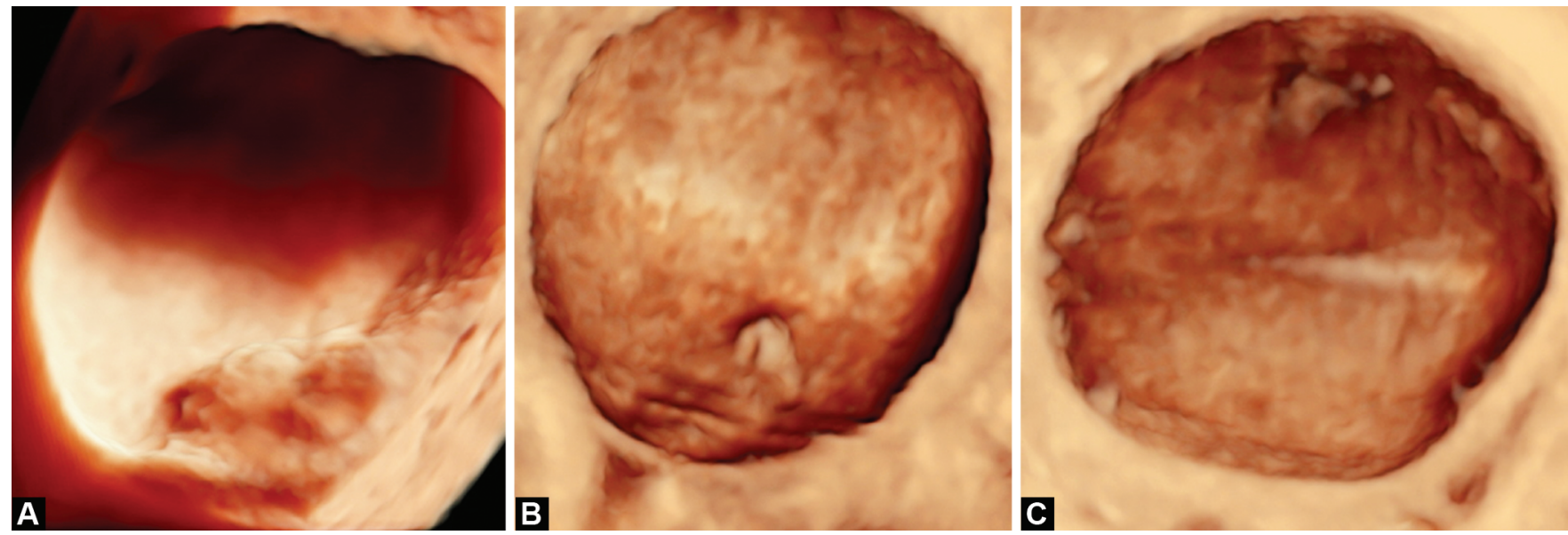

Figs $31 \mathrm{~A}$ to $\mathrm{C}$ : Cumulus presence in follicles by $3 \mathrm{D}$ US

with adverse outcomes following IVF. ${ }^{52}$ The recent study of 3D ultrasonography measuring JZ demonstrated differences in the $J Z$ thickness of women with recurrent miscarriage compared with fertile controls, ${ }^{53}$ and also the thinner JZ on the ovum pick up day leads to a higher implantation rate in intracytoplasmic sperm injection/IVF cycles ${ }^{54}$ (Fig. 36).

\section{CONCLUSION}

Vaginal US is a method of choice for initial examination in evaluating the reproductive potential of female patients. It is inexpensive, readily available, and well accepted among the patients. During recent years, technical advances in US equipment have significantly 

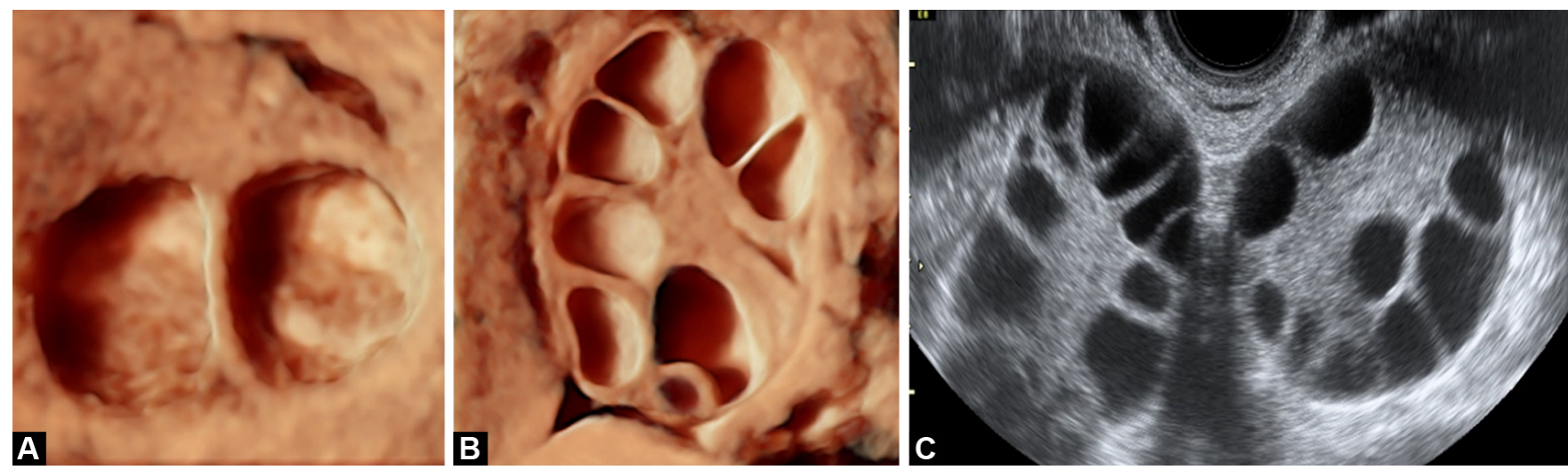

Figs 32A to C: Expression of ovarian depot during controlled ovarian stimulation: (A) Poor response; (B) Normal response; (C) Hyperresponse
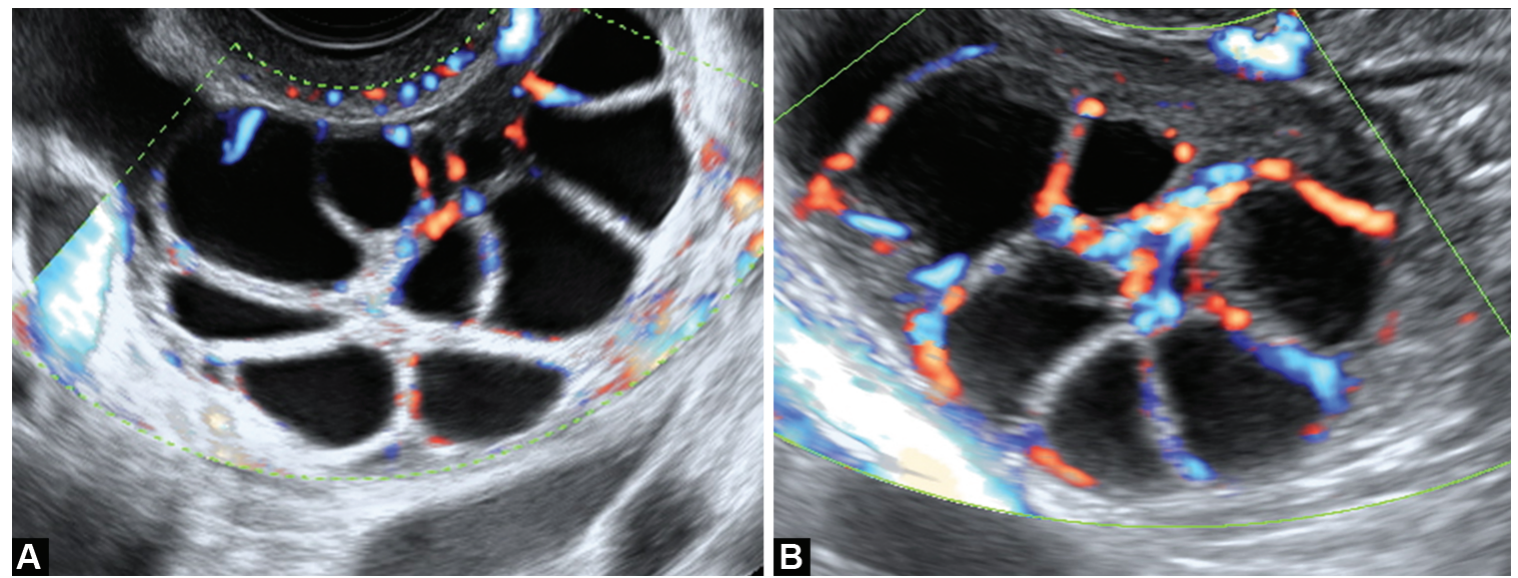

Figs 33A and B: Power Doppler scans showing different follicular vascularity from day of trigger for final oocyte maturation even though both patients are aged $<35$ years, similar BMI, same duration of controlled ovarian stimulation (COS), E2 level on day of trigger was $2750 \mathrm{vs} 2700 \mathrm{pg} / \mathrm{mL}$ and the same trigger GnRH-a was administrated. (A) 25\% circumferential flow (grade F1); (B) >75\% flow (grade F4). (Chui et al., 1997) First patient (A) on OPU day has 5 MIl oocytes, second (B) has a 19 MII oocytes on OPU day. So this is a very useful marker to detect maturity of oocytes and give a possibility to manage the duration of COS or change the trigger as a DUAL trigger for final oocyte maturation
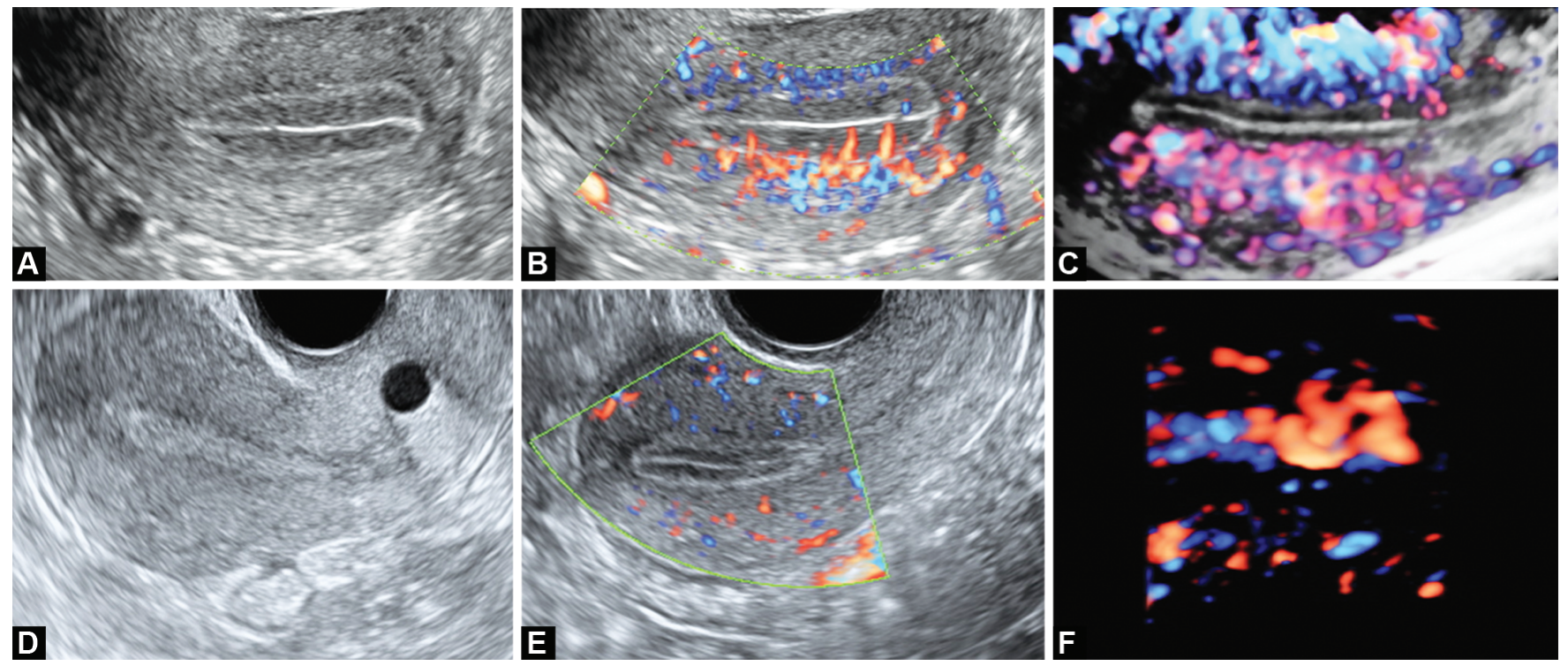

Figs 34A to F: Different endometrial thickness, endometrial morphology, endometrial and subendometrial vascularity on 2D and 3D PWD between endometrium with high receptivity $(A$ to $C$ ) and insufficient receptivity of endometrium ( $D$ to $F$ ) 

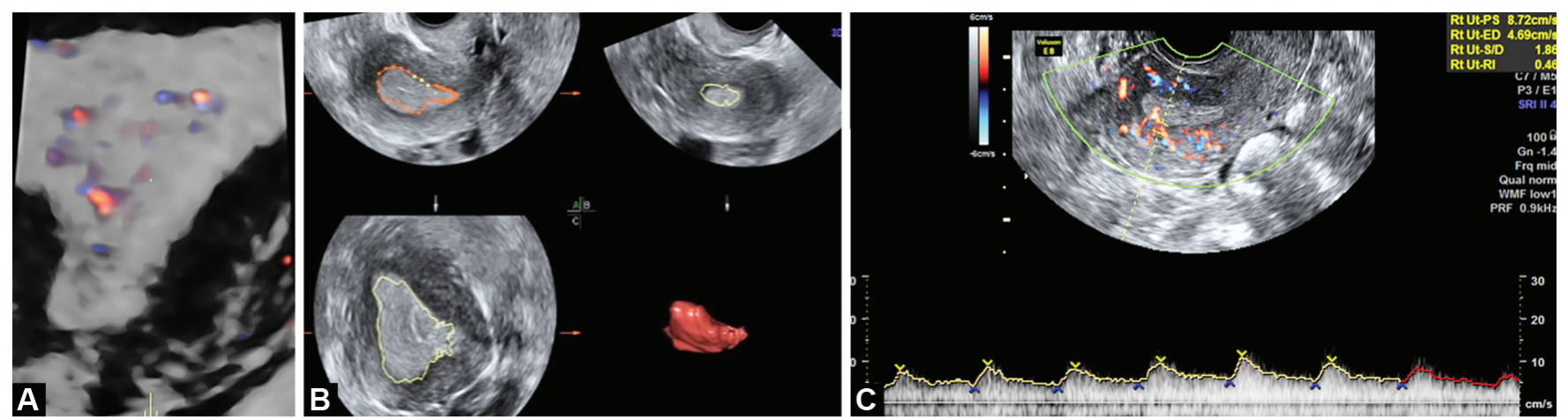

Figs 35A to C: (A) Vascular dots on 3D color Doppler vaginal ultrasound as a marker for uterine receptivity; (B) The volume of endometrium; (C) The moderate RI value and increased flow velocity indicate favorable uterine receptivity (subendometrial vessels on the day of ET)
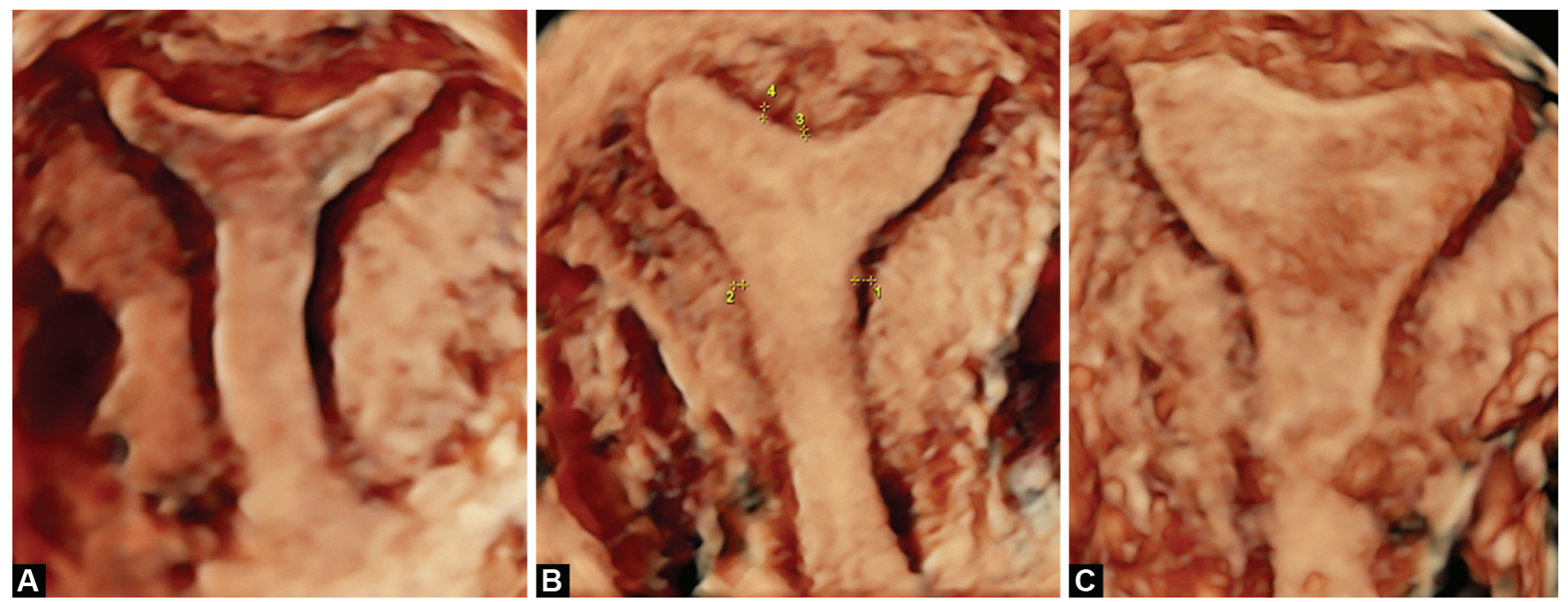

Figs 36A to C: The 3D transvaginal ultrasound showing subendometrial junction zone in coronal view of the uterus. Note the thicker JZ, (A) and thinner JZ ( $B$ and $C$ ) as the predictive markers for good implantation potential of the endometrium

improved the overall image quality. The 3D vaginal US rises the efficiency and predictive value of the examination.

\section{References}

1. Abuhamad A. Ultrasound in obstetrics and gynecology a practical approach, Ch. 11. 2014. pp. 333-237.

2. Kroon B, Johnson N, Chapman M, et al. Australasian CREl consensus expert panel on trial evidence (ACCEPT) group. Australasian CREI consensus expert panel on trial evidence. Aust NZJ, Obstet Gynaecol 2011;51(4):289-295. DOI: 10.1111/j.1479-828X.2011.01300.x.

3. Munro MG, Critchley HO, Broder MS, et al. The FIGO classification system ("PALM-COEIN") for causes of abnormal uterine bleeding in non-gravid women in the reproductive years, including guidelines for clinical investigation. Int J Gynaecol Obstet 2011;113(1):3-13. DOI: 10.1016/j.ijgo.2010.11.011.

4. Wamsteker K, Emanuel MH, de Kruif JH. Transcervical hysteroscopic resection of submucous fibroids for abnormal uterine bleeding: results regarding the degree of intramural extension 1993. Obstet Gynecol 1993;82(5):736-740.

5. Van Den Bosch T, Dueholm M, Leone FPG, et al. Terms, definitions and measurements to describe sonographic features of myometrium and uterine masses: a consensus opinion from the morphological uterus sonographic assessment (MUSA) group. Ultrasound Obstet Gynecol 2015;46(3):284-298. DOI: 10.1002/uog. 14806.
6. Kamaya A, Yu PC, Lloyd CR, et al. Sonographic evaluation for endometrial polyps the interrupted mucosa sign 2016. J Ultrasound Med 2016;35(11):2381-2387. DOI: 10.7863/ultra.15.09007|0278-4297.

7. Timmerman D, Verguts J, Konstantinovic ML, et al. The pedicle artery sign based on sonography with color Doppler imaging can replace second-stage tests in women with abnormal vaginal bleeding. Ultrasound Obstet Gynecol 2003;22(2):166-171.DOI: 10.1002/uog.203.

8. McCluggage WC. A practical approach to the diagnosis of the mixed epithelial and menzeshimallas tumors of the uterus. Mod Ptaholog 2016;29(Supp. 1):578-591.

9. Vercellini P, Parazzini F, Oldani S, et al. Surgery: adenomyosis at hysterectomy: A study on frequency distribution and patient characteristics. Human Reprod 1995;10(5):1160-1162. DOI: 10.1093/ oxfordjournals.humrep.a136111.

10. Struble J, Reid S, Bedaiwy MA. Adenomyosis: A clinical review of a challenging gynecologic condition. J Minim Invasive Gynecol 2016;23(2):164-185. DOI: 10.1016/j.jmig.2015.09.018.

11. Cunningham RM, Mindy $M$, Horrow $M$, et al. Adenomyosis: a sonographic diagnosis. Radio Graphics 2018;38(5):1576-1589. DOI: 10.1148/rg.2018180080.

12. Garcia L, Isaacson K. Adenomyosis: review of the literature. J Minim Invasive Gynecol 2011;18(4):428-437. DOI: 10.1016/j.jmig.2011.04.004.

13. Kepkep K, Tuncay YA, Göynümer G, et al. Transvaginal sonography in the diagnosis of adenomyosis: Which findings are most accurate? Ultrasound Obstet Gynecol 2007;30(3):341-345. DOI: 10.1002/ uog. 3985 . 
14. Exacoustos C, Brienza L, Di Giovanni A, et al. Adenomyosis: threedimensional sonographic findings of the junctional zone and correlation with histology. Ultrasound Obstet Gynecol 2011;37(4): 471-479. DOI: 10.1002/uog.8900.

15. Kupesic S, Kurjak A. Clinical Application of 3D Sonography. Parthenon Publishing group, 2000. pp. 200057-200059.

16. Timmerman D, Bosch TVD, Peeraer K. Vascular malformations in the uterus: ultrasonographic diagnosis and conservative management. Euro J Obstet Gynaecol Reprod Biol 2000;92(1):171-178. DOI: 10.1016/ S0301-2115(00)00443-7.

17. Timor-Tritsch IE, Haynes MC, Monteagudo A, et al. Ultrasound diagnosis and management of acquired uterine enhanced myometrial vascularity/arteriovenous malformations. Am J Obstet Gynecol 2016;214(6):731. DOI: 10.1016/j.ajog.2015.12.024.

18. Fabres C, Aviles G, De La Jara C, et al. The cesarean delivery scar pouch: Clinical implications and diagnostic correlation between transvaginal sonography and hysteroscopy. J Ultrasound Med 2003;22(7):695-700. DOI: 10.7863/jum.2003.22.7.695.

19. Tulandi T, Cohen A. Emerging manifestations of cesarean scar defect in reproductive-aged women. J Minim Invasive Gynecol 2016;23(6):893-902. DOI: 10.1016/j.jmig.2016.06.020.

20. Marotta ML, Donnez J, Squifflet J, et al. Laparoscopic repair of postcesarean section uterine scar defects diagnosed in nonpregnant women. J Minim Invasive Gynecol 2013;20(3):386-391. DOI: 10.1016/ j.jmig.2012.12.006

21. Amin TN, Saridogan E, Jurkovic D. Ultrasound and intrauterine adhesions: A novel structured approach to diagnosis and management. Ultrasound Obstet Gynecol 2015;46(2):131-139. DOI: 10.1002/uog.14927.

22. Mais V, Guerriero S, Ajossa S, et al. The efficiency of transvaginal ultrasonography in the diagnosis of endometrioma. Fertil Steril 1993;60(5):776-780. DOI: 10.1016/s0015-0282(16)56275-x.

23. Kurjak A, Prka M, Arenas JM, et al. Three-dimensional ultrasonography and power Doppler in ovarian cancer screening of asymptomatic peri- and postmenopausal women. Croatian Med J 2005;46(5): 757-764.

24. Kurjak A, Sparac V, Kupesic S, et al. Three-dimensional ultrasound and three-dimensional power Doppler in the assessment of adnexal masses. The Ultrasound Review of Obstetrics and Gynecology 2001;1(2):167-183. DOI: 10.3109/14722240108500425.

25. Somigliana E, Ragni G, Benedetti F, et al. Does laparoscopic excision of endometriotic ovarian cysts significantly affect ovarian reserve? insights from IVF cycles. Hum Reprod 2003;18(11):2450-2453. DOI: 10.1093/humrep/deg432.

26. Deenadayal M, Kadambari, Donthi S, et al. Diagnosing hydrosalpinx by three-dimensional ultrasonography in inversion mode. J Case Rep Images Obstet Gynecol 2017;3:47-50.

27. Timor-Tritsch IE, Lerner JP, Monteagudo A, et al. Transvaginal sonographic markers of tubal inflammatory disease. Ultrasound Obstet Gynecol 1998;12(1):56-66. DOI: 10.1046/j.1469-0705.1998. 12010056.x.

28. Chan YY, Jayaprakasan K, Zamora J, et al. The prevalence of congenital uterine anomalies in unselected and high-risk populations: a systematic review. Hum Reprod Update 2011;17(6):761-771. DOI: 10.1093/humupd/dmr028.

29. Nazzaro G, Locci M, Marilena M, et al. Differentiating between septate and bicornuate uterus: Bi-dimensional and 3-dimensional power Doppler findings. J Minim Invas Gynecol 2014;21(5):870-876. DOI: 10.1016/j.jmig.2014.03.023.

30. Buttram VC, Gibbons WE. Mulleriananomalies: aproposed classification (an analysis of 144 cases). Fertil Steril 1979;32(1):40-46. DOI: 10.1016/50015-0282(16)44114-2.

31. Grimbizis GF, Gordts S, Di Spiezio Sardo A, et al. The ESHRE/ESGE consensus on the classification of female genital tract congenital anomalies. Hum Reprod 2013;28(8):2032-2044. DOI: 10.1093/humrep/ $\operatorname{det} 098$.

32. Ludwin A, Ludwin I, Pityński K, et al. Arethe ESHRE/ESGE criteria of female genital anomalies for diagnosis of septate uterus appropriate? Hum Reprod 2014;29(4):867-868. DOI: 10.1093/humrep/ deu001.

33. Grimbizis GF, Di Spiezio Sardo A, Saravelos $\mathrm{SH}$, et al. The thessaloniki ESHRE/ESGE consensus on diagnosis of female genital anomalies. Hum Reprod 2016;31(1):2-7. DOI: 10.1093/humrep/dev2649,10; CUME201812 and ASRM-20162.

34. Ludwin A, Martins WP, Nastri CO, et al. Congenital uterine malformation by experts (CUME): better criteria for distinguishing between normal/arcuate and septate uterus? Ultrasound Obstet Gynecol 2018;51(1):101-109. DOI: 10.1002/uog.18923.

35. ASRM. Uterine septum: a guideline. Fertil Steril 2016;106(3):530-540. DOI: 10.1016/j.fertnstert.2016.05.014.

36. Swire MN, Castro-Aragon I, Levine D. Various sonographic appearances of the hemorrhagic corpus luteum cyst. Ultrasound Q 2004;20(2):45-58. DOI: 10.1097/00013644-20040600000003.

37. Kurjak A. Ultrasound and the ovarii, vol. 7, London: The Parthenopn publishing Group; 1994. pp. 104-105.

38. Rotterdam ESHRE/ASRM-Sponsored PCOS Consensus Workshop 2004 Group. . Revised 2003 consensus on diagnostic criteria and long-term health risks related to polycystic ovary syndrome. Fertil Steril 2004;81(1):19-25. DOI: 10.1016/j.fertnstert.2003.10.004.

39. International evidence-based guideline for the assessment and management of polycystic ovary syndrome," Accessed, 2018, https://www.monash.edu/data/assets/pdf fle/0004/1412644/PCOSEvidence-Based-Guideline.pdf.

40. Lam PM, Raine-Fenning N. The role of three-dimensional ultrasonography in polycystic ovary syndrome. Hum Reprod 2006;21(9):2209-2215. DOI: 10.1093/humrep/del161.

41. Lujan ME, Jarrett BY, Brooks ED, et al. Updated ultrasound criteria for polycystic ovary syndrome: reliable thresholds for elevated follicle population and ovarian volume. Hum Reprod 2013;28(5):1361-1368. DOI: 10.1093/humrep/det062.

42. Franks S, Webber LJ, Goh M, et al. Ovarian morphology is a marker of heritable biochemical traits in sisters with polycystic ovaries. J Clin Endocrinol Metab 2008;93(9):3396-3402. DOI: 10.1210/jc.20080369.

43. Kupesic S, et al. Sonographic imaging in infertility. Donald School textbook of transvaginal Ultrasound. 1st ed., Jaypee Brothers Medical Publishers(P) Ltd; 2005. pp. 357-383.

44. Jayaprakasan K, Chan Y, Islam R, et al. Prediction of in vitro fertilization outcome at different antral follicle count thresholds in a prospective cohort of 1,012 women. Fertil Steril 2012;98(3):657-663. DOI: 10.1016/ j.fertnstert.2012.05.042.

45. Ng EH, Chan CC, Yeung WS, et al. Effect of age on ovarian stromal flow measured by three-dimensional ultrasound with power Doppler in Chinese women with proven fertility. Hum Reprod 2004;19(9): 2132-2137. DOI: 10.1093/humrep/deh387.

46. Chui DK, Pugh ND, Walker SM, et al. Follicular vascularity-the predictive value of transvaginal power Doppler ultrasonography in an in-vitro fertilization programme: a preliminary study. Hum Reprod 1997;12(1):191-196. DOI: 10.1093/humrep/12.1.191.

47. Kupesic S, Kurjak A. Predictors of IVF outcome by three dimensional ultrasound. Hum Reprod 2002;17(4):950-955. DOI: 10.1093/ humrep/17.4.950.

48. Poehl M, Hohlagschwandtner M, Doerner V, et al. Cumulus assessment by three dimensional ultrasound for in vitro fertilization. Ultrasound Obstet Gynecol 2000;16(3):251-253. DOI: 10.1046/j.14690705.2000.0 0270.x.

49. Merce LT, Barco MJ, Kupesic S, et al. 2D and 3D power doppler ultrasound from ovulation to implantation. In: Textbook of perinatal medicine Kurjak A, Chervenak F London: Parthenon Publishing; 2005. p. 51.

50. Wu HM, Chiang $\mathrm{CH}$, Huang $\mathrm{HY}$, et al. Detection of subendometrial vascularization flow index by three dimensional ultrasound may be useful for predicting pregnancy rate for patients undergoing in vitro fertilization-embryo transfer. Fertil Steril 2003;79(3):507-511. DOI: 10.1016/S0015-0282(02)04698-8. 
51. Kupesic S, Bekavac I, Bjelos D, et al. Assessment of endometrial receptivity by transvaginal colour doppler and three dimensional power doppler ultrasonography in patients undergoing in vitro fertilization procedures. J Ultrasound Med 2001;20(2):125-134. DOI: 10.7863/jum.2001.20.2.125.

52. Maubon A, Faury A, Kapella $M$, et al. Uterine junctional zone at magnetic resonance imaging: a predictor of in vitro fertilization implantation failurejog_. J Obstet Gynaecol Res 2010;36(3):611-618. DOI: 10.1111/j.1447-0756.2010.01189.x.
53. Ng EHY, Chan CCW, Tang OS, et al. The role of endometrial and subendometrial blood flows measured by three dimensional power doppler ultrasound in prediction of pregnancy during IVF treatment. Hum Reprod 2006;21(1):164-170. DOI: 10.1093/humrep/ dei277.

54. Lazzarin N, Exacoustos C, Vaquero E, et al. Uterine junctional zone at three-dimensional transvaginal ultrasonography in patients with recurrent miscarriage: A new diagnostic tool? Eur J Obstet Gynecol Reprod Biol 2014;174:128-132. DOI: 10.1016/j.ejogrb.2013.12.014. 